九州大学学術情報リポジトリ

Kyushu University Institutional Repository

\title{
Morphology of Crystals Grown from Highly Supersaturated Solution
}

Aoki, Yoshikazu

Faculty of Science, Kyushu University

https://doi.org/10.5109/1544208

出版情報：九州大學理學部紀要：Series D, Geology. 24 (2)，pp.75-108，1979-11-10. Faculty of Science, Kyushu University バージョン:

権利関係 : 
Mem. Fac. Sci., Kyushu Univ., Ser. D. Geol., Vol. XXIV, No. 2, pp. $75-108$, text-figs. 1-25, table 1, pl. 14, November 10, 1979

\title{
Morphology of Crystals Grown from Highly Supersaturated Solution
}

\author{
Yoshikazu AOKI
}

\begin{abstract}
The habit of crystals grown from highly supersaturated solution has been formed to be governed by linkages of coordination polyhedra from a morphological analysis on the basis of crystal structure. Such a vector of linkages having a direction and an energetical period which represents the three dimensional structure may well be called a linkage vector. A face including at least two non-parallel linkage vectors and being parallel or nearly parallel to some faces of coordination polyhedra becomes an important face. Seven examples of the morphological analysis by this method are given. This method can give a qualitative estimation of the concentration change of mineralizing solution and also a reasonable explanation on the mechanism of formation of growth twins.
\end{abstract}

\section{Contents}

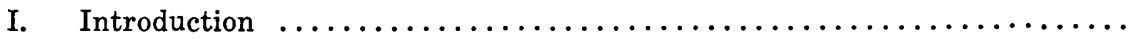

II. Outline of the Method of Linkages of Coordination Polyhedra (LCP

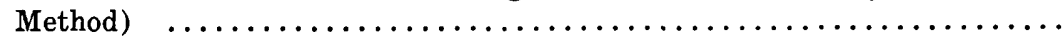

III. Some Examples of Crystal Habit Deduced by Linkage Vector Analysis of

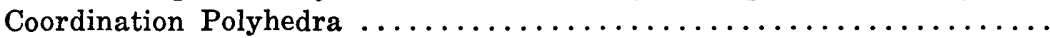

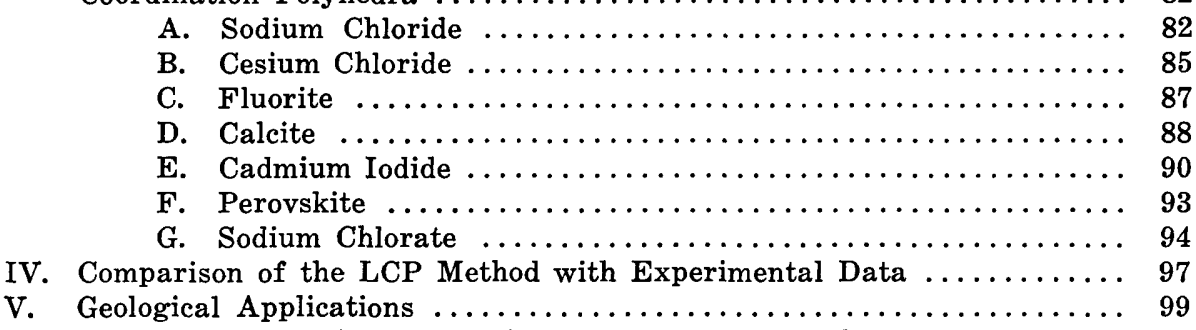

A. Qualitative Estimation of Concentration Change of Mineraliz-

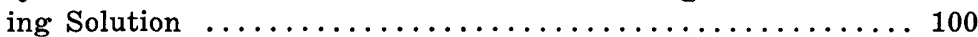

B. Mechanism of Formation of Growth Twins ........... 103

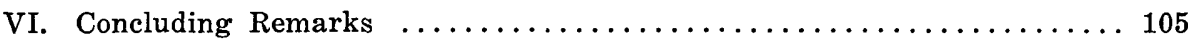

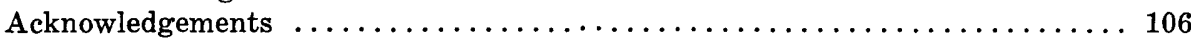

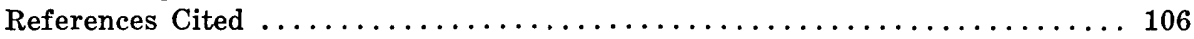

\section{Introduction}

One of the characteristic properties of crystals is that each crystal has its own habit, namely, each crystal is bounded by a series of plane faces. These faces usually appear to have some regularity.

$\overline{\text { Manuscript received July }}$ 3, 1979. 
The crystal habit and its regularity have been noted and studied by many investigators from old times. The earliest account on the relations among the actual faces of a crystal was given by GoLDSCHMIDT (1897). He stated that the faces of a crystal could be grouped together into certain zones, and the faces developed in a zone between two intersections with other zones could be represented by a "normal series". He called this rule "law of complication".

BAUMHAUER $(1904,1925)$ modified the complication law of GoLDSCHMIDT by introducing an idea of "strength" of faces, but this did not attract much attention because of the newly developed crystallographic applications of X-rays.

These earlier theories are concerned with the development of a zone. In order to consider all the faces of a crystal, FrIEDEL (1907) applied the principle of BravaIs (1866), and concluded that the order of development of the faces was in agreement with an order of reticular densities of the possible faces. FEDOROV $(1912,1920)$ also developed nearly the same idea.

In 1919, NIGGLI indicated the influence of glide planes and screw axes on the reticular density, and advanced a theory that the development of a face was dependent on the "depth of the unsaturated layer". This depth means the distance between the outermost and the innermost layers which contain unsaturated building units. It is denoted by $\Delta_{h k l}$ and is zero or a multiple of $d_{h k l}$ according to NigGLI (1920). At the same time, he pointed out the importance of statistical studies in crystal habit.

Later, DONNAY and HARKER (1937) rediscovered the influence of the glide planes and screw axes on the reticular density. The consideration of this influence was able to account for many anomalies in the old law of BRAVAIs. DoNNAY (1937) showed also that the above-mentioned studies of BAUMHAUER was a theoretical consequence and a factual confirmation of the law of BRAVAIs.

From the restricted crystallographic approach, WELLS (1946) emphasized thermodynamics and the concept of the equilibrium form. From the fact that the crystal habit was modified experimentally by change of environment, he considered the "morphological aspects" (ranking of forms in order of importance). He assumed a physical association of atoms with the DONNAY-HARKER equipoints and rejected the DONNAY and HARKER's approach. His complaint is that they limited their generalization of the law of BRAVAIS to space group symmetry without any consideration of the intensity distribution as in X-ray structure analysis. WELLS also stated that the assumption of GIBBS (1906) was a good working hypothesis and that the different habits of a crystal were caused by the different surface energies. In several examples, he demonstrated the large influence of environment to crystal growth.

Similarly to the consideration of WELLS, BUERGER (1947) noted the parallelism between form development and X-ray diffraction. BUERGER proposed the model of growth by molecular blocks, which assumes that residual surface energies related inversely to the interplanar spacings. But, like WELLs, BUERGER gave no practical method by which the influence of energy factors could be taken into account.

HARTMAN (1953) and Hartman and PeRdok (1955) presented some theore- 
tical considerations, which made it possible to correlate the crystal habit and the crystal structure from the qualitative estimation of bond energies. Their conclusion is that the habit of a crystal is governed by chains of strong bonds which run through the structure in a limited number of directions. The energetical period of such a chain of strong bonds is called a periodic bond chain vector (PBC vector), and faces of a crystal are divided into three classes, $F, S$, and $K$ faces by PBC vector analysis. HARTMAN (1956a, 1959, etc.), Simon and Bienfait (1965), and BESSIERES and BARo (1973) have reported successful applications of this approach.

On the other hand, environmental influences on crystal habit have been developed by many investigators from old times (for examples ; BuNN, 1933; BunN, 1949 ; etc.). KERN $(1953 ; 1955 ; 1969)$ showed in a number of experiments that ionic crystals might change their habit when the supersaturation exceeded a certain critical value. He also showed that, in order to obtain a habit modification, a critical supersaturation had to be exceeded in some extent which depends on the concentration of the impurity in the solution. In a plot of the supersaturation against the impurity concentration, lines can be drawn which separate fields with different crystal habit. Such a plot is called a morphodrome (BIENFAIT et al., 1963).

KERN tried to explain the influence of the supersaturation and the impurity adsorption on the habit change of crystals. He made some thermodynamical explanations about the influence of the latter. However, he could not give any theoretical considerations about the influence of the former. Needless to say, HARTMAN's theory can not be employed for the enough discussion of the influence of those on the crystal habit.

The aim of this study is to give a general explanation to some morphological facts in terms of the crystal structure and linkages of the coordination polyhedra, especially in the field of crystal growth from highly supersaturated solution.

\section{Outline of the Method of Linkage of Coordination Polyhedra (LCP Method)}

(1) Crystals grow from liquid or vapor. Hence at first, it is necessary to know the behavior of crystallizing materials in liquid or vapor.

For example, it is an important problem how cations and anions distribute in solution. Two factors may play an important role in mutual distribution of ions in solution, namely, thermal collisions and electrostatic attractive forces among ions having opposite electric charges.

The number of ions present at a distance of $r$ from an $\alpha$-ion is calculated as follows by using Boltzmann's formula:

$$
n_{i}(r)=n_{i} \exp \left(-\frac{q_{i} \psi_{a}}{k T}\right)
$$

where $n_{i}(r)$ and $n_{i}$ are the number of $i$-th ions per unit volume existing at the distance of $r$ from the $\alpha$-ion in bulk solution, respectively, $q_{i}$ is the electric charge of an $i$-th ion, $\phi_{a}$ is the electric potential, $k$ is the Boltzmann's constant, and $T$ is 
the absolute temperature. The relative probability of the existence of $i$-th ions at the distance of $r$ from the $\alpha$-ion becomes from formula (1):

$$
\frac{n_{i}(r)}{n_{i}}=\exp \left(-\frac{q_{i} \psi_{a}}{k T}\right)
$$

$\psi_{\alpha}$ is determined by DEBYE and HÜCKEL (1923) as a formula showing an average electric potential of a distance $r$ from the center of the $\alpha$-ion:

$$
\phi_{a}=\frac{q_{\alpha}}{D(1+\kappa a) r} \exp [-\kappa(r-a)]
$$

in which $q_{\alpha}$ is the electric charge of the $\alpha$-ion, $D$ is the dielectric constant of the solvent, $a$ is the nearest distance between two ions, and

$$
\kappa^{2}=\frac{4 \pi \sum_{i} N_{i} q_{i}{ }^{2}}{D V k T}
$$

in which $N_{i}$ is the number of $i$-th ions and $V$ is the unit volume of solution.

Here, let us introduce the ionic strength defined by the following formula:

$$
I=\frac{1}{2} \sum_{i} m_{i} z_{i}{ }^{2}=\frac{1}{2 d_{s}} \sum_{i} c_{i} z_{i}^{2}
$$

in which $m_{i}, c_{i}$ and $z_{i}$ are the molality, molarity and ionic valence of the $i$-th ion, respectively, and $d_{s}$ is the density of the solvent.

When (5) is substituted in (4), we obtain the following relation:

$$
\kappa^{2}=\frac{4 \pi N e^{2}}{1000 D k T} \sum_{i} c_{i} z_{i}{ }^{2}=\frac{8 \pi N^{2} e^{2} d_{s}}{1000 D R T} \times I
$$

in which $e$ is the elementary electric charge, and $R$ is gas constant.

When (3) and (6) are substituted in (2), we can obtain the relative probability of the distribution of ions in relation to the distance from an $\alpha$-ion and the concentration of ions.

The result of the calculation is shown in Fig. 1 taking the $\alpha$-ion as positive monovalent, the $i$-th ion as negative monovalent, and $a=3.0 \AA$ at $25^{\circ} \mathrm{C}$. Fig. 1 clearly shows a marked tendency that negative ions cluster around a positive ion.

The clustering of ions in solution has been observed experimentally from about the end of 1950's. For example, BRADY (1958) measured X-ray scattering from $\mathrm{Fe}-\mathrm{Cl}$ solution in the concentration range from $1.5 \mathrm{M}$ to $5 \mathrm{M}$. He obtained a result that at the highest concentration the $\left[\mathrm{FeCl}_{6}\right]^{3-}$ ion appeared to be the main species, but as the concentration was lowered the coordination of the $\mathrm{Cl}^{-}$ ions around $\mathrm{Fe}^{3+}$ became less definite.

(2) It seems that these phenomena will be extended to highly supersaturated region. In addition, the ion distribution in solution must approach that of a molten salt as already reported by some investigators about highly concentrated aqueous electrolytes (HESTER et al., 1964; HESTER et al., 1967; IRISH et al., 1968). In a molten salt, the long-range periodicity of ion distribution as in a crystal is absent, but the interionic distances and the coordination numbers are known to be similar to those in the crystal (LEvy et al., 1964).

If there is a coordination polyhedron round a cation in highly supersaturated solution, it is reasonable to presume that cations in solution are concentrated to combine with anions of the polyhedron. Then, anions in solution will gather to 


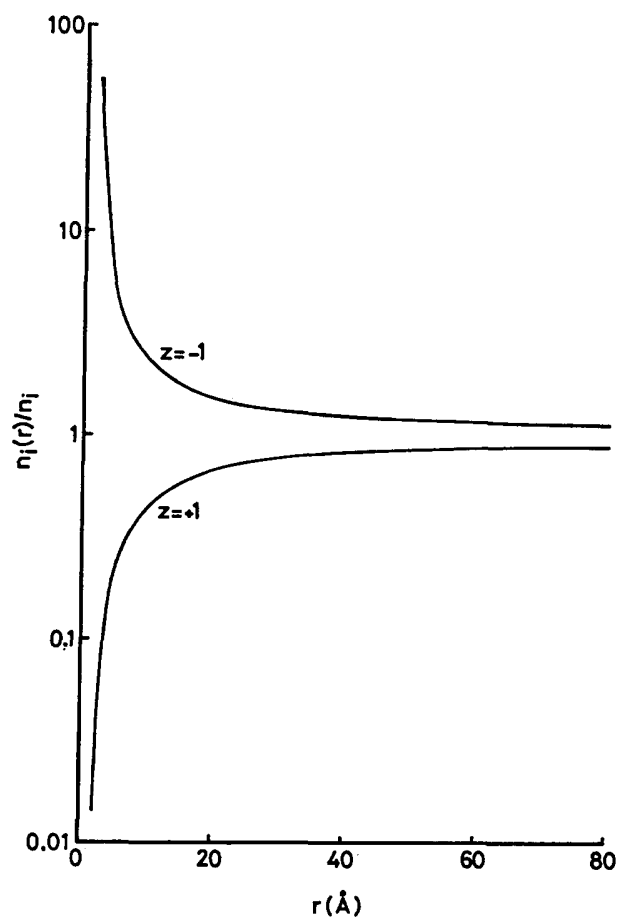

Fig. 1. Ionic density change round an ion of charge te by DEBYE-DüCKEL theory.

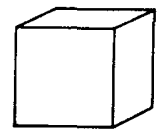

A

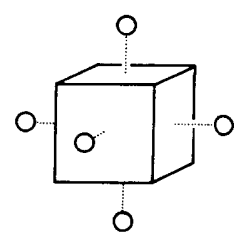

B

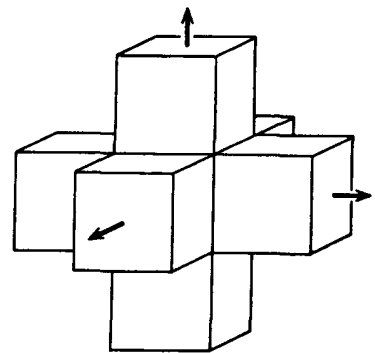

C

Fig. 2. The proposed growth sequence of a crystal of composition MX in higher supersaturation. A cube and an open circle indicate a coordination polyhedron round an $\mathrm{M}^{+}$ion and an $\mathrm{M}^{+}$ion, respectively.

form the coordination polyhedra round each cations already combined with anions of the already existed polyhedron. In this manner, a crystal will grow from the highly supersaturated solution.

For example, let us consider a crystal of composition MX growing from the highly supersaturated solution. $\mathrm{M}$ and $\mathrm{X}$ are a monovalent cation and an anion, respectively, and each $\mathrm{M}^{+}$ion is symmetrically surrounded by eight $\mathrm{X}^{-}$ions and each $\mathrm{X}^{-}$ion is similarly surrounded by eight $\mathrm{M}^{+}$ions, i.e. both are cubic coordination, respectively. Hence, the coordination cubes link by sharing faces. 
Let's assume that a coordination cube round an $\mathbf{M}^{+}$ion is present in the highly supersaturated solution (Fig. 2-A). Under the condition that the ion distribution in solution is similar to that of the molten salt, cations are expected to concentrate to form the coordination cubes such as those in the crystal. Such a position of cations is the nearest neighbour one from anions of the coordination cube, as shown in Fig. 2-B. After cations make bonds with anions of the coordination cube, anions in solution will soon concentrate at the nearest neighbour positions from the cations just described above and will make bonds with the cations to form coordination cubes, as shown in Fig. 2-C.

In this manner, a crystal will grow from the highly supersaturated solution. Namely, crystal growth will continue in the direction of the arrows (Fig. 2-C), which is the same direction as linkages of coordination polyhedra. Hence, when a crystal growth occurs in highly supersaturated solution, it is presumed that a crystal will grow along the direction of linkages of coordination polyhedra.

(3) The corodination polyhedra in crystals can be classified by the kind of the central atoms, coordination number, and the forms of the polyhedron. And there are three ways of linkages among them, namely, sharing corners, edges, and faces. We will find one or more linkings in a given structure. Here, we can define a linkage unit. The linkage unit is defined as a fundamental linkage between two neighbouring coordination polyhedra. It is unequivocally dependent upon the kind and the form of coordination polyhedra and their three-dimensional arrangement in a structure.

For example, let us consider a structure made up by coordination rectangular prisms sharing faces each other. There are two kinds of linkage unit shown as broken lines (a) and (b) in Fig. 3, in which a linkage unit is indicated as a line between the central atoms of neighbouring polyhedra for convenience. Although two linkages are in the same way of sharing faces, the energetical views are different. The distance between the central atoms is longer in the case of (b) than in that of (a), therefore, the repulsion between atoms of the same kind is stronger in the latter case than in the former one. The linking phenomena between the

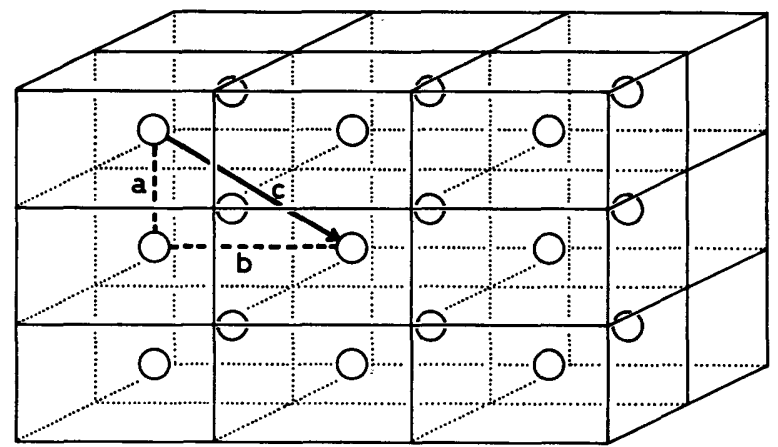

Fig. 3. Schematic illustration of a structure having an array of coordination prism. Broked lines (a) and (b) and a thick line (c) between the central atoms of neighbouring polyhedra show the linkage units and the linkage vector, respectively. 
two cases will energetically be different when a crystal grows. Consequently, we must distinguish them as two different linkage units.

When a crystal has only one kind of linkage unit, the crystal growth might be taken place along the directions of the linkage unit. However, many crystals have two or more kinds of linkage unit in the structure. In this case, it is considered that the crystal will grow along the directions of the combination of these linkage units to construct a given structure. A combination is shown as a sum of linkage units. We will call this sum a linkage vector. A linkage vector has a given length (a period) and a crystallographic direction. In Fig. 3, a linkage vector is indicated as a thick line (c) between the two central atoms. It is the sum of linkage unit (a) and (b).

Former case in which a crystal has only one kind of linkage unit is the particular case that the linkage vector is identical with the linkage unit.

Consequently, the crystal growth may be taken place along the directions of the linkage vectors when the solution is highly supersaturated. If two or more non-parallel linkage vectors are present in a layer, the layer becomes flat. A crystal made up by these flat planes has a habit of the crystal grown from the highly supersaturated solution.

(4) Therefore, we can assume that the habit of crystals grown from the highly supersaturated solution is determined by the direction of the linkage of the coordination polyhedra. Then, we can deduce the crystal habit from the crystal structure by using the linkage of the coordination polyhedra.

The application of this method may be usually done in several stages as follows :

Firstly, consider a three-dimensional crystal structure as an array of coordination polyhedra.

Secondly, some linkage units are sought in it.

Thirdly, linkage vectors must be sought from the linkage units.

Fourthly, when the linkage vectors have been found, they can be drawn in a stereogram as zone circles corresponding to their directions. If there are faces containing two or more non-parallel linkage vectors in a layer, they will develop as important faces when a crystal grows in the highly supersaturated solution as described above. In a stereogram, they are found as the points of intersections of these zone circles.

Fifthly, when two or more faces of forms have been found to develop as important ones, the faces of all the coordination polyhedra* must be projected on the same stereogram. When the pole is projected as the same point as the intersection points of some zone circles in it, the face or form will develop as important one. The other ones may be difficult to develop as flat faces or forms. They can not be flat because edges and/or corners of coordination polyhedra appear on their surfaces, and they will have some properties like kinked or stepped faces rather than flat ones.

* Actually, surfaces of coordination polyhedra may have some unevenness for the electron cloud of anions. But, in this case we can assume a surface surrounded by some: lines connecting central points of anions as flat plane. 


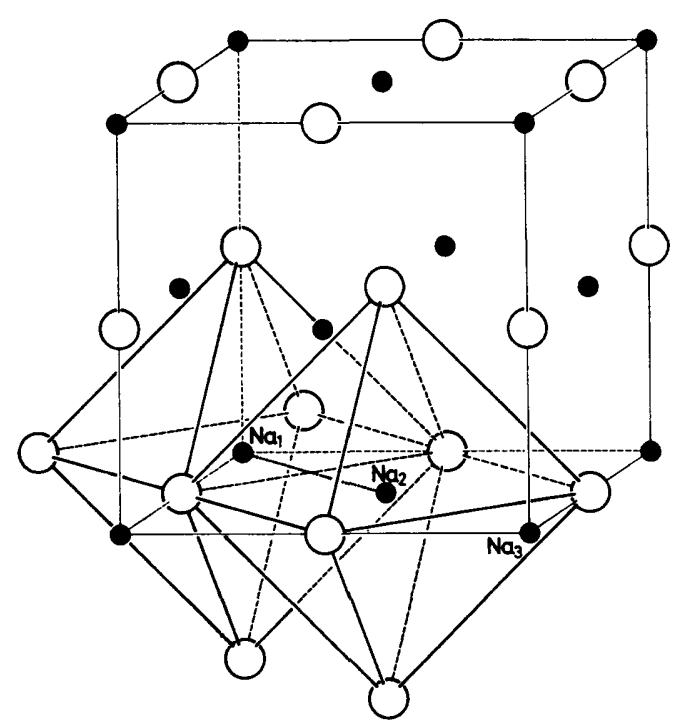

Fig. 4. Crystal structure of sodium chloride. The thin lines and the thick lines indicate the unit cell of sodium chloride and the coordination octahedra round $\mathrm{Na}^{+}$ions, respectively. A dotted line between $\mathrm{Na}_{1}$ and $\mathrm{Na}_{2}$ shows a linkage unit which corresponds to a linkage vector in this case.

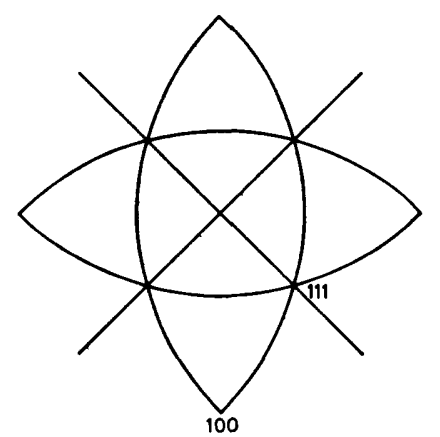

Fig. 5. Streographic projection of the linkage vectors in sodium chloride structure. The directions of the linkage vectors are represented by their corresponding zone circles.

More detailed explanations are presented for some examples in the following chapter.

\section{Some Examples of Morphology Deduced by Linkage Vector Analysis of Coordination Polyhedra}

\section{A. Sodium Chloride}

The structure of sodium chloride has a cubic cell with space group $F m 3 m$ (WYCKoFf, 1963). The $\mathrm{Na}^{+}$ions are situated at the corners and at the face 


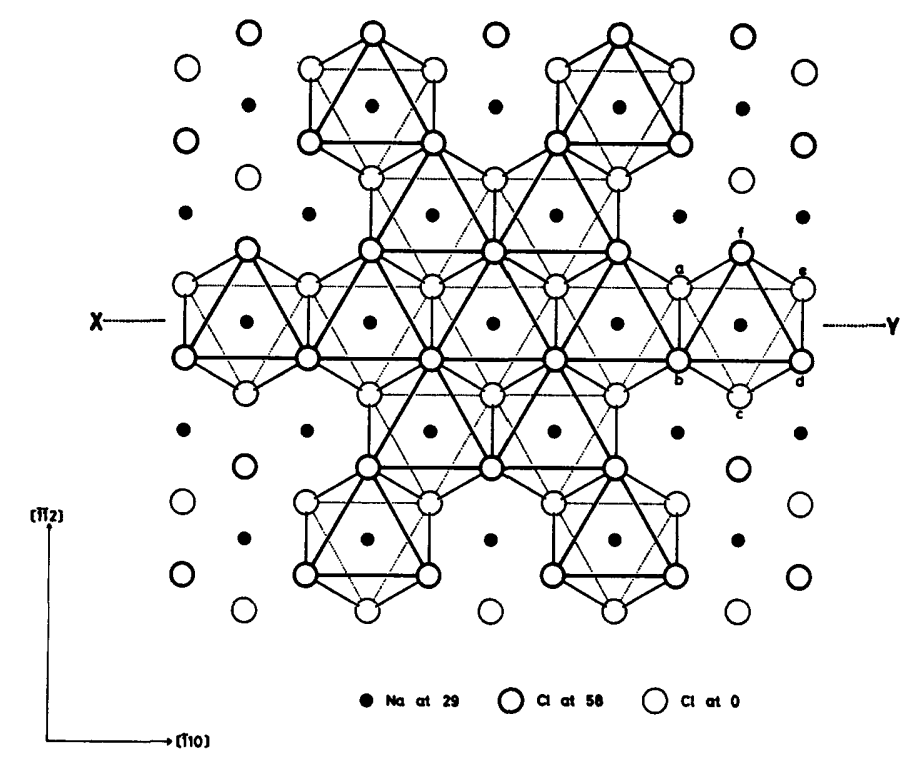

A

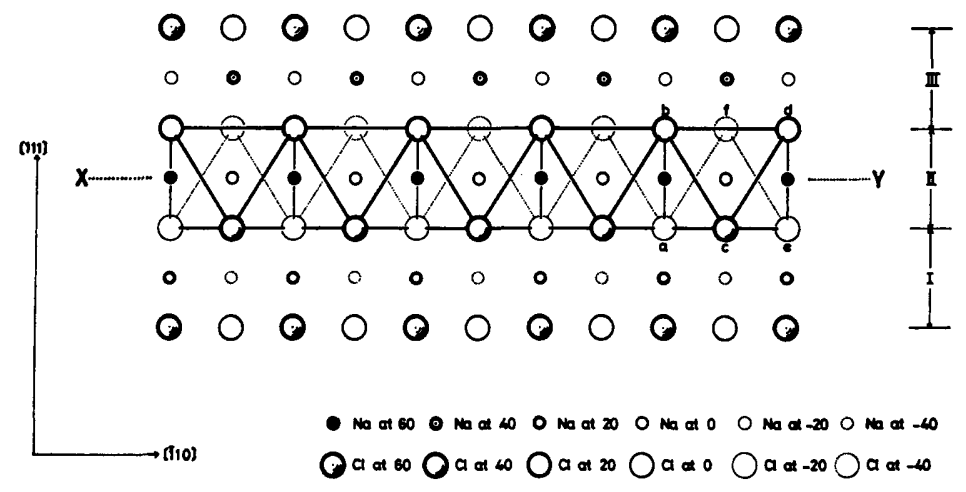

B

Fig. 6. Linking aspect of coordination octahedra round $\mathrm{Na}^{+}$ions in the sodium chloride structure.

A. (111) projection of the structure of the layer-II in Fig. 6-B.

B. The vertical sectional view taken on line $\mathrm{X}-\mathrm{Y}$ of Fig. 6-A.

centers of the unit cell. The $\mathrm{Cl}^{-}$ions occur at the edges of the unit cell and at the center of the cube.

Each $\mathrm{Na}^{+}$ion is symmetrically surrounded by six $\mathrm{Cl}^{-}$ions, and it has regular octahedral coordination. Each $\mathrm{Cl}^{-}$ion is similarly surrounded by six $\mathrm{Na}^{+}$ions. The structural aspect is illustrated in Fig. 4, where the regular octahedra of Clions about each $\mathrm{Na}^{+}$ion are shown. It becomes clear from Fig. 4 that each of the octahedra shares every one of its twelve edges with neighbouring octahedra.

It is easily understood that there is only one kind of linkage among neigh- 


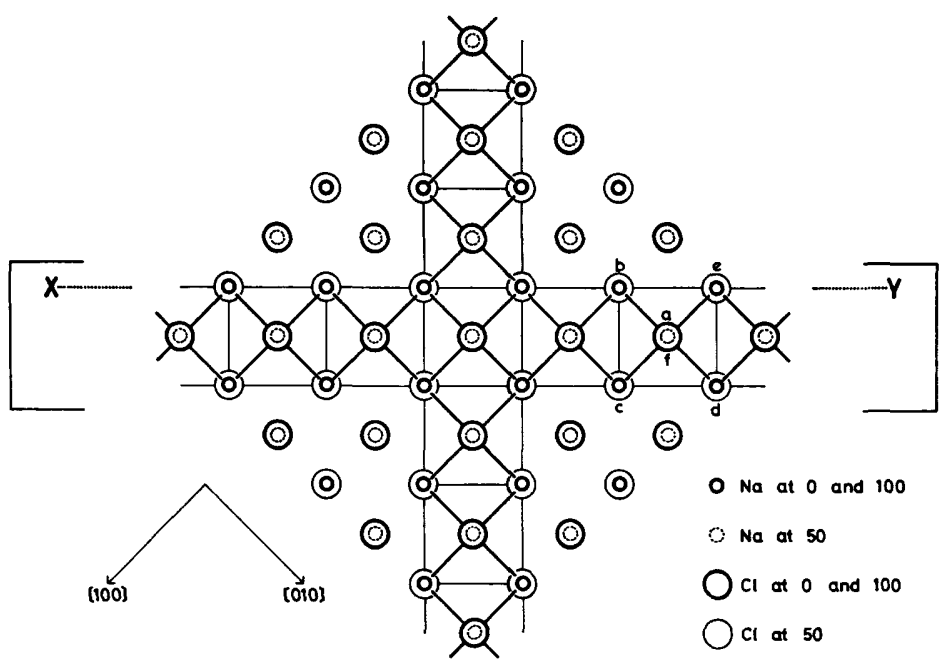

A

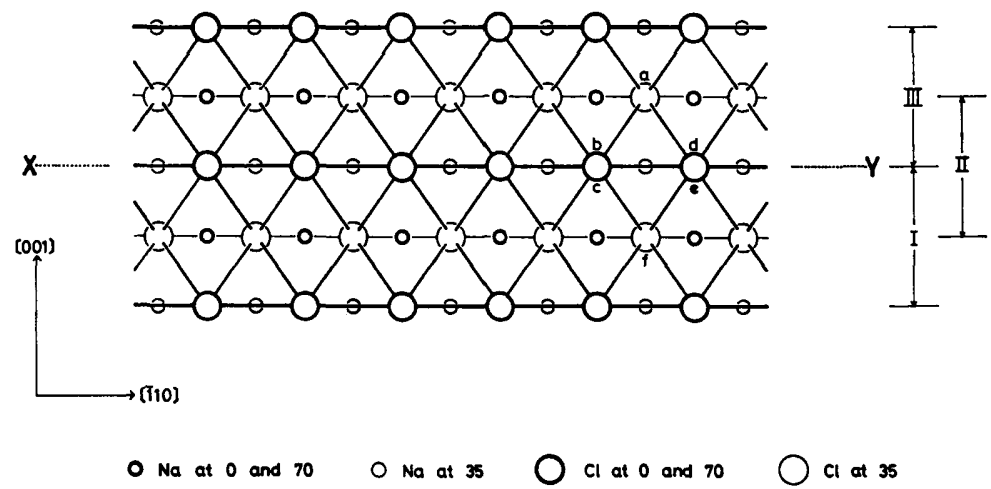

B

Fig. 7. Linking aspect of coordination octahedra round $\mathrm{Na}^{+}$ions in the sodium chloride structure.
A. (001) projection of the sodium chloride structure.
B. The vertical sectional view of bracketted part of Fig. 7-A taken on line $\mathrm{X}-\mathrm{Y}$.

bouring octahedra about each $\mathrm{Na}^{+}$ion, namely, a linkage of sharing edges having the linkage unit from $\mathrm{Na}_{1}$ to $\mathrm{Na}_{2}$. This linkage unit determines a linkage vector directed to $\langle 110\rangle$.

Solid lines in Fig. 5 show the zone circles corresponding to the directions of the linkage vectors in sodium chloride structure. They intersect at $\{111\}$ and $\{100\}$ points. Hence, $\{111\}$ and $\{100\}$ are expected to be the important forms on 


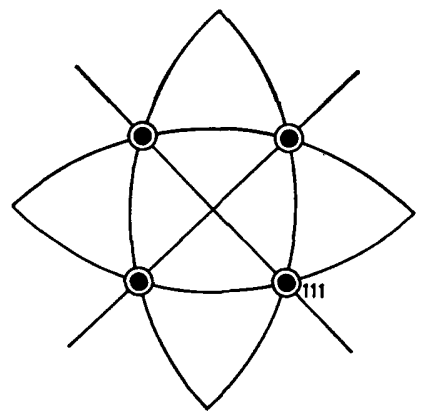

Fig. 8. Stereographic projection of zone circles corresponding to the directions of the linkage vectors and of the faces of coordination octahedra round $\mathrm{Na}^{+}$ions in the sodium chloride structure.

sodium chloride crystals grown from the highly supersaturated solution, because the two forms include three and two non-parallel linkage vectors in a layer, respectively.

Fig.6-A illustrates the sodium chloride structure projected on (111), and Fig. 6-B is its vertical sectional view taken on line $\mathrm{X}-\mathrm{Y}$ of Fig. 6-A. But in Fig. 6-A, only layer-II in Fig. 6-B is projected on (111). In these figures, one octahedron round $\mathrm{Na}^{+}$ion is marked by abcdef. The edges marked $\overline{\mathrm{ac}}, \overline{\mathrm{ce}}$, and $\overline{\mathrm{ea}}$ are shared with octahedra of an underlying layer-I (Fig. 6-B). Six edges of $\overline{a b}, \overline{b c}, \overline{c d}, \overline{d e}$, $\overline{\text { ef, }}$ and $\overline{\mathrm{fa}}$, are shared with neighbouring octahedra belonging to the same layerII. From these three-dimensional arrangements of octahedra, it is understood that there are three directions of linkages of octahedra sharing edges and they intersect at an angle of $120^{\circ}$ each other as shown in Fig. 6-A.

On the other hand, there are two directions of linkages of octahedra in $\{100\}$, and they intersect at right angles. Those are shown in Fig. 7-B which illustrates the vertical sectional view of the bracketted part of Fig. 7-A taken on line $\mathrm{X}-\mathrm{Y}$. The edges of $\overline{\mathrm{bf}}, \overline{\mathrm{cf}}, \overline{\mathrm{df}}$, and $\overline{\text { ef }}$ are shared with octahedra of a lower layer-I, and the edges of $\overline{b c}, \overline{c d}, \overline{d e}$, and $\overline{e f}$ are shared with neighbouring octahedra in the layer-II.

As described above, $\{111\}$ and $\{001\}$ have three and two non-parallel linkage vectors, respectively. But, morphologically $\{111\}$ is only one important form, because poles of the faces of the coordination octahedra are plotted at the same points of $\{111\}$ on a stereogram as shown in Fig. 8.

Consequently, when a sodium chloride crystal grows from the highly supersaturated solution, $\{111\}$ is expected to appear as an important form.

\section{B. Cesium Chloride}

The structure of cesium chloride has a cubic cell with space group $P m 3 m$ (WYCKOFF, 1963). The $\mathrm{Cs}^{+}$and $\mathrm{Cl}^{-}$ions occur at the center and at the corners of the unit cell, respectively.

Each $\mathrm{Cs}^{+}$ion is symmetrically surrounded by eight $\mathrm{Cl}^{-}$ions. And each $\mathrm{Cl}^{-}$ ion is similarly surrounded by eight $\mathrm{Cs}^{+}$ions. Hence both ions are cubic coordi- 


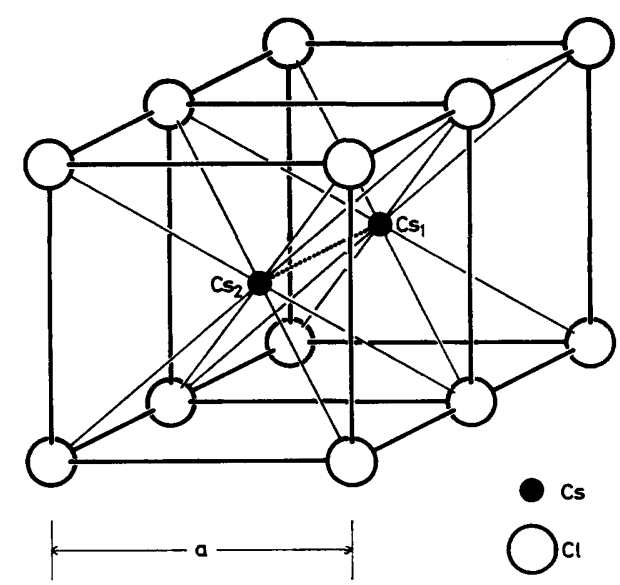

Fig. 9. Crystal structure of cesium chloride. The thick lines indicate the coordination cubes round $\mathrm{Cs}^{+}$ions, and a dotted line between $\mathrm{Cs}_{1}$ and $\mathrm{Cs}_{2}$ shows a linkage vector in this case.

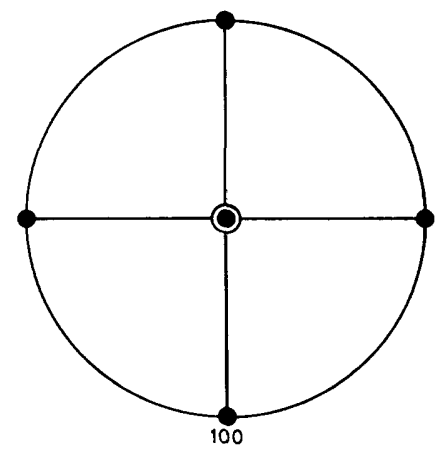

Fig. 10. Stereographic projection of zone circles corresponding to the directions of the linkage vector and of the faces of coordination cubes round $\mathrm{Cs}^{+}$ions in the cesium chloride structure.

nation, respectively. This aspect of the structure is shown in Fig. 9, where the neighbouring two cubes of $\mathrm{Cl}^{-}$ions round each $\mathrm{Cs}^{+}$ion are shown.

There is only one kind of linkages among neighbouring cubes round $\mathrm{Cs}^{+}$, namely the linkage of coordination cubes sharing faces. The linkage unit is from $\mathrm{Cs}_{1}$ to $\mathrm{Cs}_{2}$ as shown by a dotted line in Fig. 9. This linkage unit determines a linkage vector directed to $\langle 100\rangle$.

The directions of the linkage vectors are indicated by their corresponding zone circles in the stereographic projection as shown in Fig. 10. They intersect at $\{100\}$ points. And the poles of faces of the coordination cube are projected at the same points. Hence, $\{100\}$ is the important form for cesium chloride crystals grown from the highly supersaturated solution. 


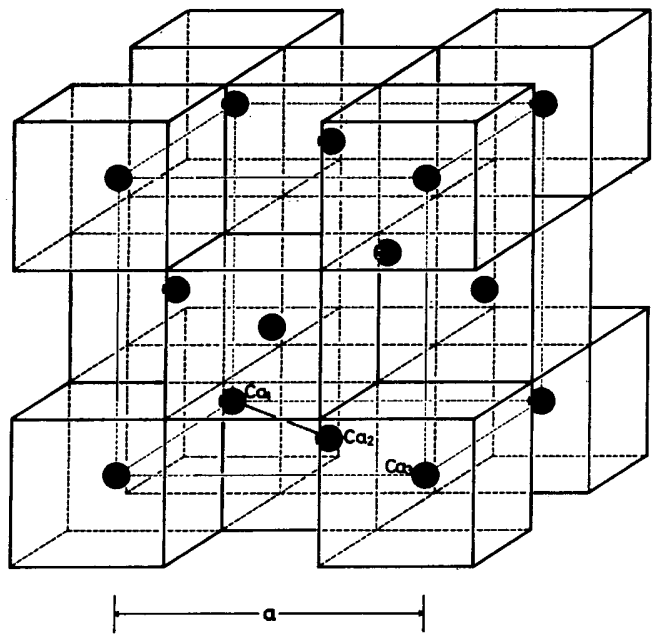

A
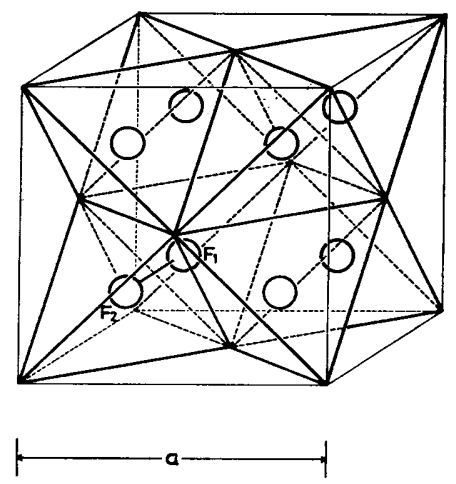

B

Fig. 11. Crystal structure of fluorite.

A. Fluorite structure as an array of coordination cubes round $\mathrm{Ca}^{2+}$ ions. A line between $\mathrm{Ca}_{1}$ and $\mathrm{Ca}_{2}$ indicates the linkage unit.

B. Fluorite structure as an array of coordination tetrahedra round $\mathrm{F}^{-}$ions.

A line between $F_{1}$ and $F_{2}$ indicates the linkage unit.

\section{Fluorite}

The structure of fluorite has a cubic cell with space group $F m 3 m$ (WYCKoFF, 1963). The $\mathrm{Ca}^{2+}$ ions are arranged at the corners and face centers of a cubic unit cell, and $\mathrm{F}^{-}$ions are at the centers of the eight cubelets into which the cell may be divided.

Therefore, each $\mathrm{Ca}^{2+}$ ion is surrounded by eight $\mathrm{F}^{-}$neighbours at the corners of a cube (Fig. 11-A), while each $\mathrm{F}^{-}$ion is coordinated by four $\mathrm{Ca}^{2+}$ neighbours at the corners of a regular tetrahedron (Fig. 11-B). The cubes of $\mathrm{F}^{-}$ions about each $\mathrm{Ca}^{2+}$ ion are linked with neighbouring cubes by sharing edges having a linkage unit from $\mathrm{Ca}_{1}$ to $\mathrm{Ca}_{2}$ as shown in Fig. 11-A. The linkage unit determines linkage vector having a direction of $\langle 110\rangle$.

In the case of the linkages of tetrahedra round $\mathrm{F}^{-}$ions, there is only one kind of linkages of tetrahedra sharing edges. The linkage unit from $F_{1}$ to $F_{2}$ is shown by a line in Fig. 11-B. It determines a linkage vector $\langle 100\rangle$.

In Fig. 12-A, and Fig. 12-B zone circles corresponding to the linkage vectors determined by the linkages of coordination cubes round $\mathrm{Ca}^{2+}$ ion and tetrahedra round $\mathrm{F}^{-}$ion are illustrated in stereographic projections, respectively.

In Fig. 12-A, zone circles intersect at the points of $\{100\}$ and $\{111\}$. The poles of the faces of coordination cube are projected at the same points as $\{100\}$, and not as $\{111\}$. Hence, $\{100\}$ is the important form, in this case.

While, in Fig. 12-B, zone circles intersect at the points of $\{100\}$, but the faces 


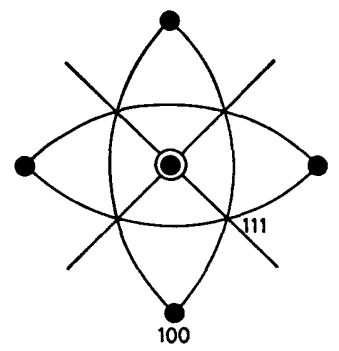

A

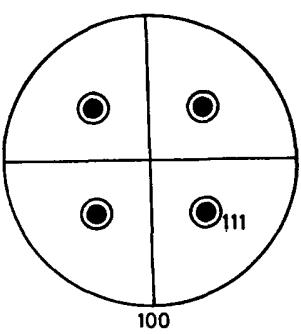

B

Fig. 12. Stereographic projections of zone circles corresponding to the directions of the linkage vectors and of the faces of coordination cubes round $\mathrm{Ca}^{2+}$ ions $(\mathrm{A})$ and those of coordination tetrahedra round $\mathrm{F}^{-}$ions $(\mathrm{B})$ in the fluorite structure.

of coordination tetrahedra are plotted at the points of $\{111\}$. Hence $\{100\}$ is difficult to be a flat form because intersection points of zone circles are not projected at the same points as the poles of the faces of coordination tetrahedra on the same stereogram.

Consequently, when a fluorite crystal grows under the condition of linking the coordination cubes round $\mathrm{Ca}^{2+}$ ion, $\{100\}$ is expected to appear as the important form.

\section{Calcite}

Calcite has a rhombohedrally-centered hexagonal lattice. In certain cases rhombohedral axes of reference giving a primitive unit cell have been chosen. However we use hexagonal axes of reference in the following discussion because they are much convenient to use than rhombohedral ones.

It has been said that when calcite grows from solution, carbon and oxygen atoms in solution act as if they were a divalent $\mathrm{CO}_{3}{ }^{2-}$ ion (for example, LIPPMAN, 1973). And the structure of calcite is held together by the electrostatic forces between the component ions $\mathrm{Ca}^{2+}$ and $\mathrm{CO}_{3}{ }^{2-}$ (BRAGG, 1914).

Therefore, it is better to consider the structure of calcite as an array of coordination polyhedra constructed by $\mathrm{Ca}^{2+}$ and $\mathrm{CO}_{3}{ }^{2-}$ from each segregated layers in alternate levels, perpendicular to the $c$-axis and spaced at $1 / 2$ of its length. And basal $\mathrm{Ca}$ and $\mathrm{CO}_{3}$ layers of calcite correspond to the octahedral $\mathrm{Na}$ and $\mathrm{Cl}$ planes of sodium chloride structure (Fig. 4). Hence each $\mathrm{Ca}$ is surrounded by six $\mathrm{CO}_{3}$ as well as $\mathrm{Na}$ surrounded by six $\mathrm{Cl}$ in sodium chloride structure (Fig. 13). The resulting octahedron is flattened in the direction of the hexagonal $c$-axis.

The octahedra share edges with neighbouring octahedra. There is only one kind of linkage unit, but this determines two linkage vectors with the same period but different directions. One of them is the vector from $\mathrm{Ca}_{1}$ to $\mathrm{Ca}_{2}$ as shown by a dotted line (a) in Fig. 13. This vector has the direction of $\langle 11 \overline{2} 0\rangle$. The other one is the vector from $\mathrm{Ca}_{1}$ to $\mathrm{Ca}_{3}$, a line $\left(a^{\prime}\right)$ in Fig. 13, and has the direction of $\langle 01 \overline{1} 2\rangle$. 


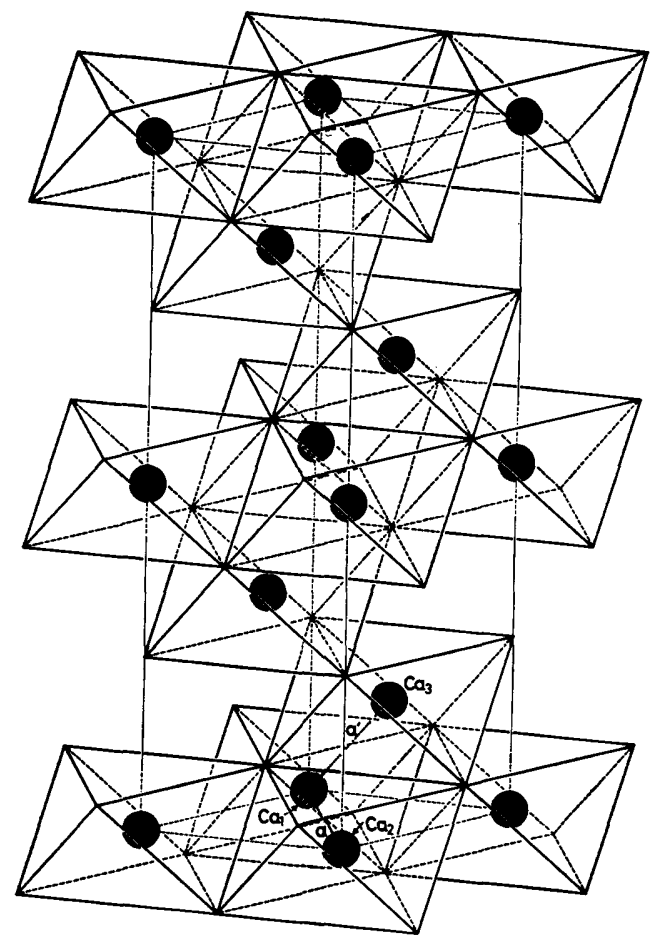

Fig. 13. Crystal structure of calcite as an array of coordination octahedra round $\mathrm{Ca}^{2+}$ ions. Dotted lines (a) and $\left(\mathrm{a}^{\prime}\right)$ between $\mathrm{Ca}_{1}$ and $\mathrm{Ca}_{2}$ and between $\mathrm{Ca}_{1}$ and $\mathrm{Ca}_{3}$, respectively, indicate two linkage vectors in calcite structure.

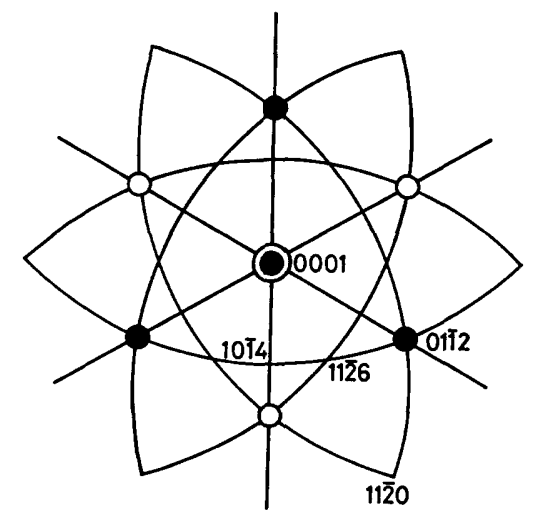

Fig. 14. Stereographic projection of zone circles corresponding to the directions of the linkage vectors and of the faces of coordination octahedra round $\mathrm{Ca}^{2+}$ ions in calcite structure.

When zone circles corresponding to the direction of the vectors are projected on a stereogram, they intersect at the points of $\{0001\},\{01 \overline{1} 2\} .\{11 \overline{2} 0\},\{1 \overline{1} 6\}$, and $\{10 \overline{1} 4\}$ (Fig. 14). While the poles of faces of coordination octahedra are plotted at $\{0001\}$ and $1 / 2\{01 \overline{1} 2\}$. Hence $c\{0001\}$ is the most important form and e $1 / 2\{01 \overline{12}\}$ 
is the secondary important form. It is predicted that $\{0001\}$ develops widely and the sides are truncated by $1 / 2\{01 \overline{1} 2\}$ when a calcite crystal grows in the highly supersaturated solution.

\section{E. Cadmium Iodide}

Cadmium iodide has a layer structure consisting of planes of $\mathrm{Cd}$ atoms and
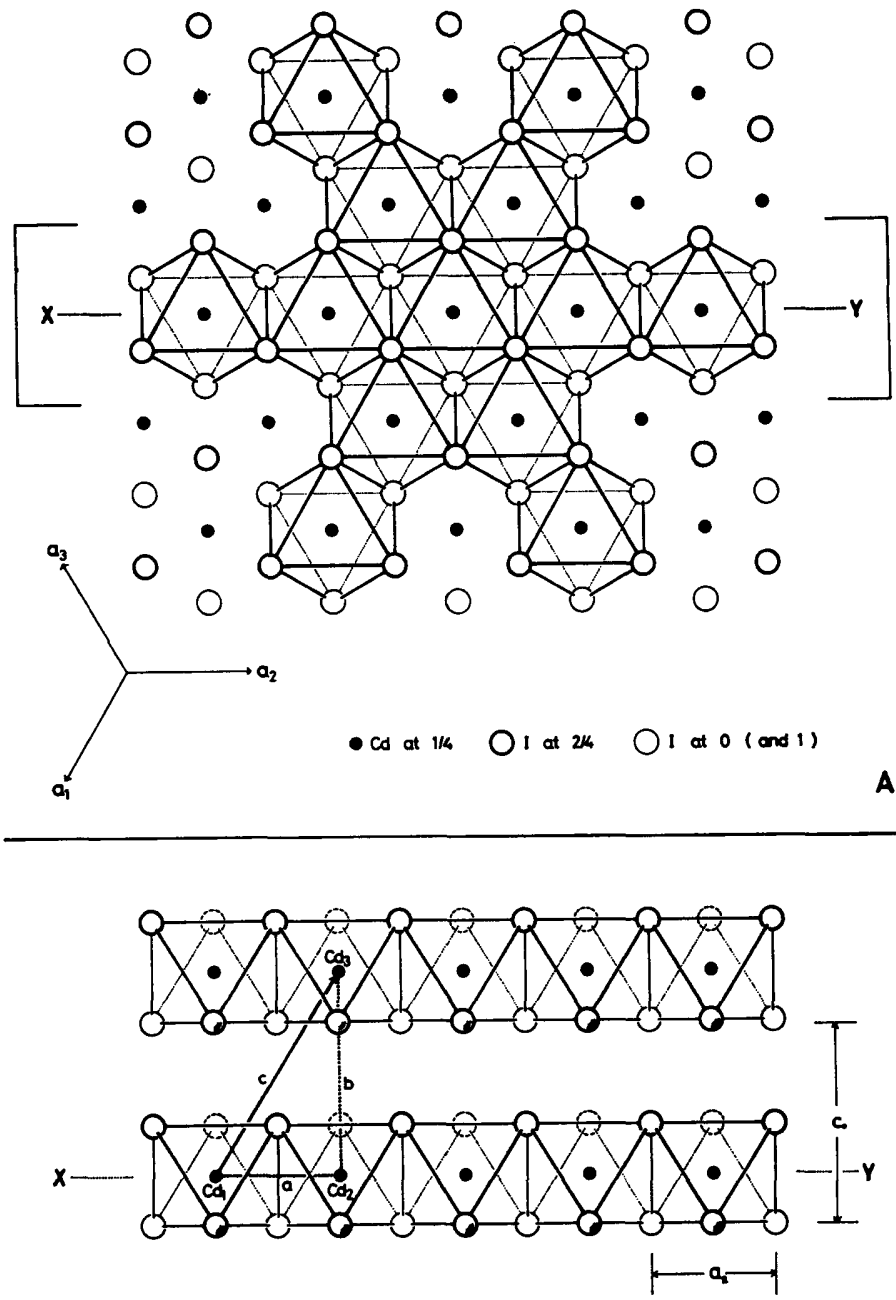

ca 0

O i a $56 \quad 01$ at $19 \quad 01$ at $-19 \quad 01$ at -56

B

Fig. 15. Linking aspect of coordination octahedra round $\mathrm{Cd}$ atoms in cadmium iodide structure.

A. Projection on (0001).

B. The vertical sectional view of the bracketted part of Fig. 15-A taken on line X-Y. Dotted lines (a) and (b) between $\mathrm{Cd}_{1}$ and $\mathrm{Cd}_{2}$ and between $\mathrm{Cd}_{2}$ and $\mathrm{Cd}_{3}$ indicate two linkage units, respectively, and a broad line (c) between $\mathrm{Cd}_{1}$ and $\mathrm{Cd}_{3}$ is the linkage vector. 
I atoms. The planes of $\mathrm{Cd}$ atoms are sandwitched between the planes of $\mathrm{I}$ atoms in the $z$-direction.

Each Cd atom is surrounded by six I atoms forming a slightly flattened octahedron. Fig. 15-A illustrates the linking aspect of the octahedra round Cd projected on (0001), and Fig. 15-B is the vertical sectional view of the bracketted part of Fig. 15-A taken on line $\mathrm{X}-\mathrm{Y}$. As shown in Fig. 15, octahedra round Cd
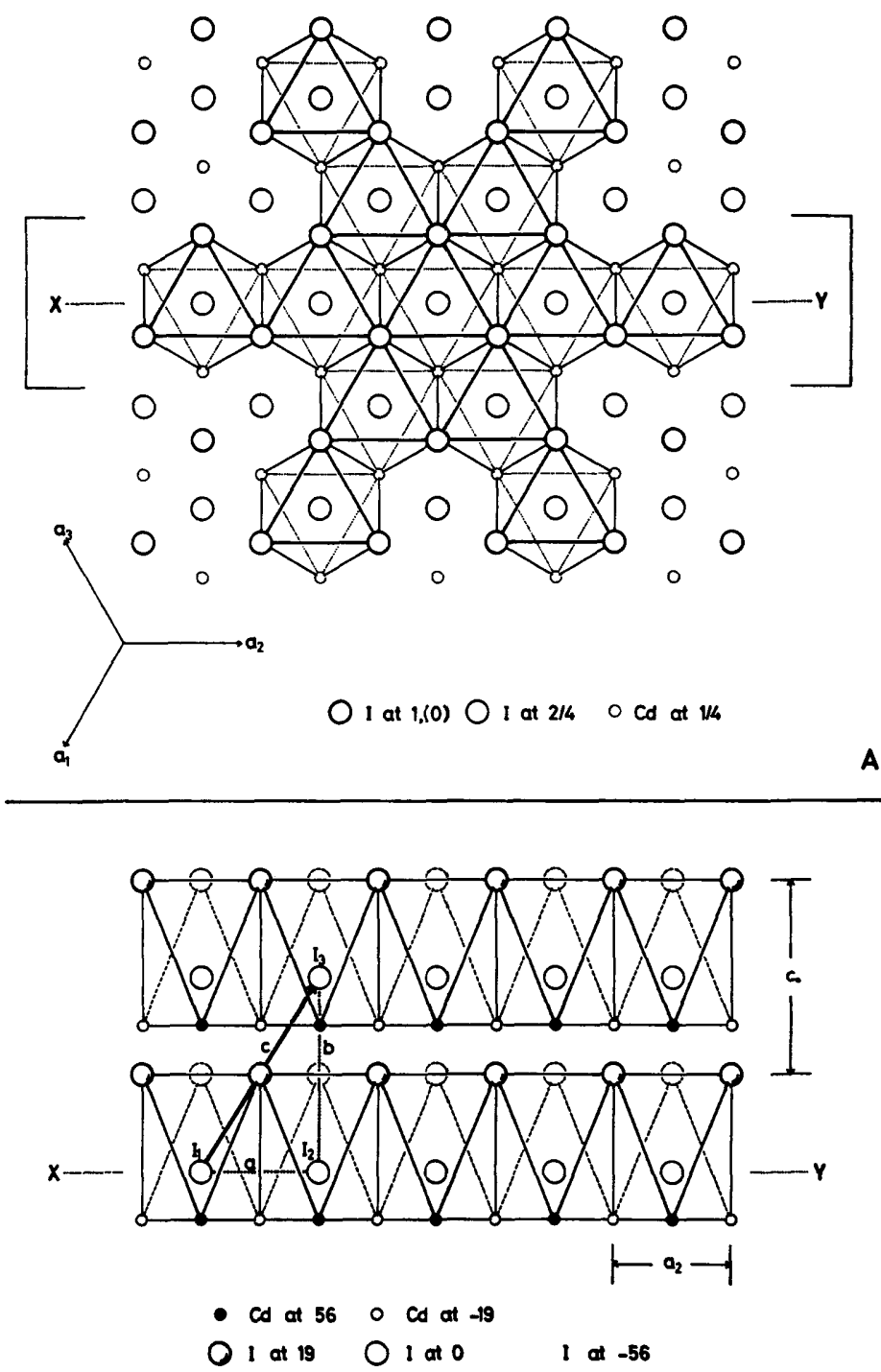

B

Fig. 16. Linking aspect of coordination octahedra round I atoms in cadmium iodide structure.

A. Projection on (0001).

B. The vertical sectional view of the bracketted part of Fig. 16-A taken on line $\mathrm{X}-\mathrm{Y}$. 


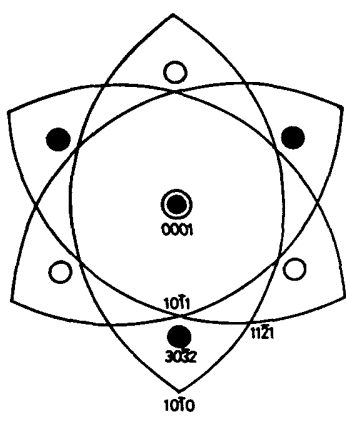

A

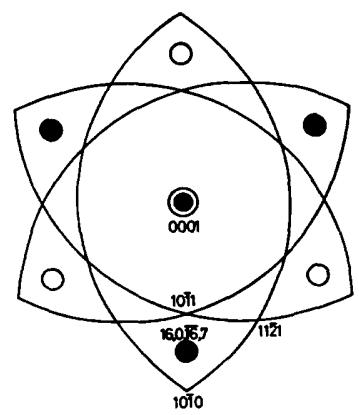

B

Fig. 17. Stereographic projection of zone circles corresponding to the directions of the linkage vectors and of the faces of coordination octahedra round $\mathrm{Cd}$ atoms (A) and round I atoms (B).

in a same layer link together by sharing edges with neighbouring octahedra. But, octahedra in one layer are linked with those of the upper or lower layer by van der Waals forces between those layers.

Consequently, there are two units in cadmium iodide structure as shown by dotted lines (a) from $\mathrm{Cd}_{1}$ to $\mathrm{Cd}_{2}$ and (b) from $\mathrm{Cd}_{2}$ to $\mathrm{Cd}_{3}$ in Fig. 15-B. These linkage units determine a linkage vector, which is shown as a thick line (c) from $\mathrm{Cd}_{1}$ to $\mathrm{Cd}_{3}$ in the same figure.

On the other hand, each I atom has six neighbours, three Cd atoms on one side and three I atoms on the other forming an elongated octahedron. These aspects are illustrated in Fig. 16. Fig. 16-A shows the linking aspect of the octahedra round I projected on (0001), and Fig. 16-B is the vertical sectional view of the bracketted part of Fig. 16-A taken on line $\mathrm{X}-\mathrm{Y}$. By linking with sharing edges, octahedra round I consist a layer in the $x y$ plane, and the layer contacts with the next $\mathrm{CdI}_{2}$ layer in the $z$-direction. Hence, there are two linkage units, a dotted line (a) from $I_{1}$ to $I_{2}$ and (b) from $I_{2}$ to $I_{3}$, and these linkage units determine a linkage vector, a broad line (c) from $I_{1}$ to $I_{3}$, as shown in Fig. 16-B.

The linkage vector (c) in Fig. 16-B has the same length and the same direction as those in Fig. 15-B. When the zone circles corresponding to the directions of the linkage vector are projected on stereograms, they intersect at the points of $\{10 \overline{1} 1\},\{10 \overline{10}\}$, and $\{112 \overline{1}\}$, but the poles of faces of octahedron round Cd and round $I$ are not projected on these points in both cases as shown in Fig. 17.

In the case of octahedron round $\mathrm{Cd}$, the faces are projected at $\{0001\}$ and $1 / 2\{30 \overline{3} 2\}$ (Fig. 17-A). Between the, $1 / 2\{30 \overline{3} 2\}$ is located at the point of $8^{\circ} 36^{\prime}$ apart from $\{10 \overline{1} 1\}$, and $\{10 \overline{1} 1\}$ will be able to develop as an important form, although the surface is not completely flat.

On the other hand, the faces of octahedron round I are projected at $\{0001\}$ and $1 / 2\{16,0, \overline{16}, 7\}$. The former form will not develop as an important form as can be seen in Fig. 17-B. And the latter ones is located at the point of $13^{\circ} 23^{\prime}$ and $14^{\circ} 51^{\prime}$ apart from $\{10 \overline{1} 0\}$ and $\{10 \overline{1} 1\}$, respectively. From this fact, both $\{10 \overline{1} 0\}$ and $\{10 \overline{1} 1\}$ are not able to develop as flat forms. 


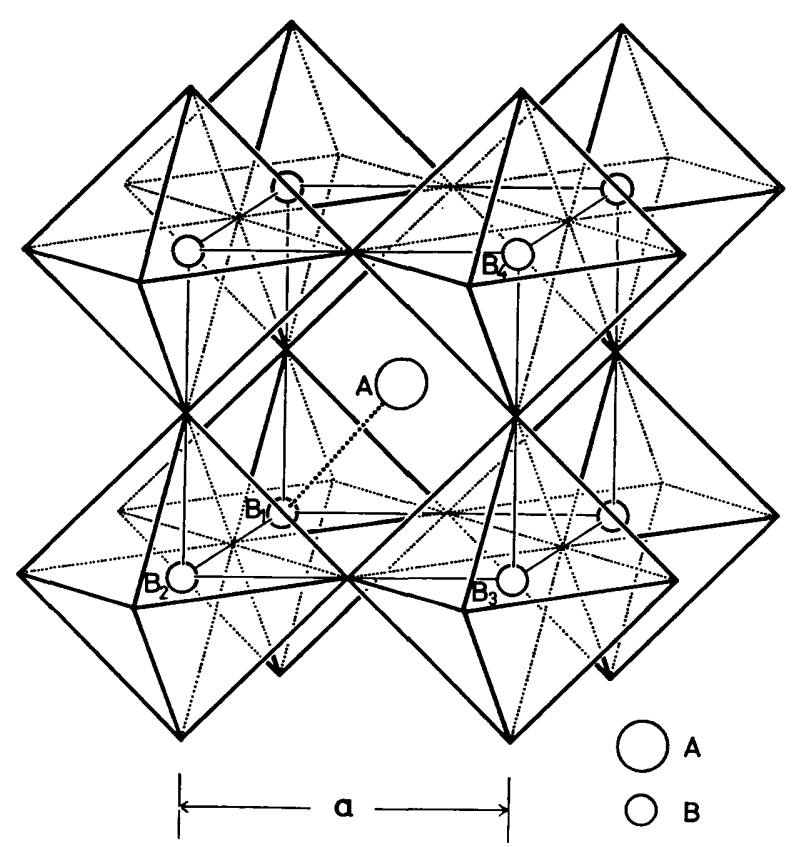

Fig. 18. Ideal perovskite structure as an array of coordination octahedra round $\mathrm{B}$ atoms and cuboctahedron round $\mathrm{A}$ atom.

Therefore, $\{10 \overline{1} 1\}$ is expected to appear as the form although not completely flat, when a $\mathrm{CdI}_{2}$ crystal grows under the condition linking the coordination octahedra round $\mathrm{Cd}$.

\section{F. Perovskite}

This is an example of a structure containing two different coordination polyhedra round two different cations.

Mineral perovskite actually has a complicated structure, but we treat here the perovskite structure as the ideal one.

The structure, with general formula $\mathrm{ABX}_{3}$, consists essentially of a frame work of $\mathrm{BX}_{6}$ octahedra linked by their corners, with a large $\mathrm{A}$ cation occupying a cavity of the same size as an $X$ anion. As shown in Fig. 18, each $B$ cation is surrounded by six $\mathrm{X}$ atoms and each $\mathrm{A}$ by $12 \mathrm{X}$ atoms, octahedron and cuboctahedron in shape, respectively. In this figure, $\mathrm{X}$ atoms are located at the corners of the octahedra, although not illustrated by circles. All octahedra are in parallel orientation in the case of the ideal perovskite structure, $\mathrm{SrTiO}_{3}$ for example.

There is only one linkage unit, $B_{1}-A$ in Fig. 18. This determines three linkage vectors having the directions from $B_{1}$ to $B_{2}\langle 100\rangle$, from $B_{1}$ to $B_{3}\langle 110\rangle$, and from $\mathrm{B}_{1}$ to $\mathrm{B}_{4}\langle 111\rangle$.

The zone circles corresponding to the directions of the linkage vectors are drawn in Fig. 19. They intersect at the points of $\{111\},\{100\},\{110\}$, and $\{112\}$.

On the other hand, the poles of faces of octahedron round $B$ cation and of 


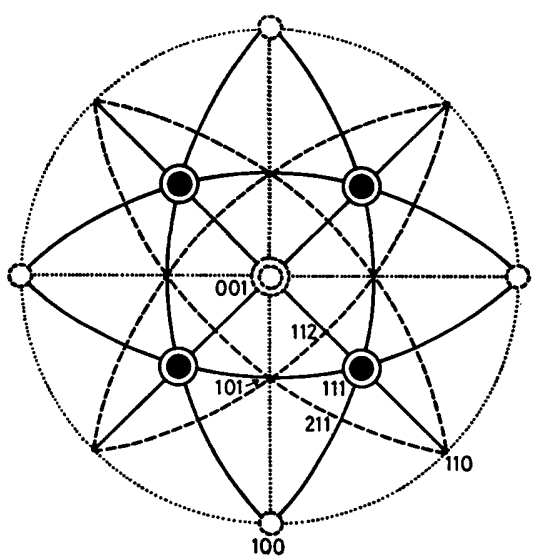

Fig. 19. Stereographic projection of zone circles corresponding to the linkage vectors directed to $\langle 100\rangle$ (dotted lines), $\langle 110\rangle$ (solid lines), and $\langle 111\rangle$ (broken lines). The faces of octahedra round $B$ atoms (solid and open circles) and of cuboctahedra round $\mathrm{A}$ atoms (circles drawn by broken lines) are also shown.

cuboctahedron round A cation are located at the points of $\{111\}$, and $\{111\}$ and $\{100\}$, respectively.

Hence $\{111\}$ and $\{100\}$ are expected to appear as the important forms when a perovskite crystal grows in the highly supersaturated solution.

\section{G. Sodium Chlorate}

Sodium chlorate, $\mathrm{NaClO}_{3}$, is also an example of a structure containing two different coordination polyhedra like perovskite but distorted.

It has an $\mathrm{NaCl}$ arrangement of its ions distorted to accomodate the $\mathrm{ClO}_{3}$ anions in such a way that the symmetry remains cubic (WYCKOFF, 1963). Each $\mathrm{Na}^{+}$ion is surrounded by six oxygen atoms to form a distorted octahedron and $\mathrm{ClO}_{3}$ ion is a flat trigonal pyramid having the three oxygen atoms of its base.

Their arrangement is illustrated in Fig. 20. The octahedron shares corners with neighbouring trigonal pyramid. There are four linkage units in the sodium chlorate structure, because the octahedron round $\mathrm{Na}$ is distorted and $\mathrm{ClO}_{3}$ trigonal pyramids about $\mathrm{Cl}_{1}$ and $\mathrm{Cl}_{2}$ have not the same orientation in reference to a-axis. Those are the units from $\mathrm{Na}(0,0,0)$ to $\mathrm{Cl}_{1}$, from $\mathrm{Cl}_{1}$ to $\mathrm{Na}(1,0,0)$, from $\mathrm{Na}$ $(0,0,0)$ to $\mathrm{Cl}_{2}$ to $\mathrm{Na}(0,1,0)$.

The former two and the latter two determine the linkage vectors having the direction of [100] and [010], respectively. However, neither of the two linkage vectors could not construct the structure of sodium chlorate with only one vector itself. Therefore, they are the auxiliary linkage vectors. A principal linkage vector being able to construct the structure is the sum of them. In the case of sodium chlorate, it is a vector having the direction of $\langle 110\rangle$, from $\mathrm{Na}(0,0,0)$ to $\mathrm{Na}(1,1,0)$ in Fig. 20. 


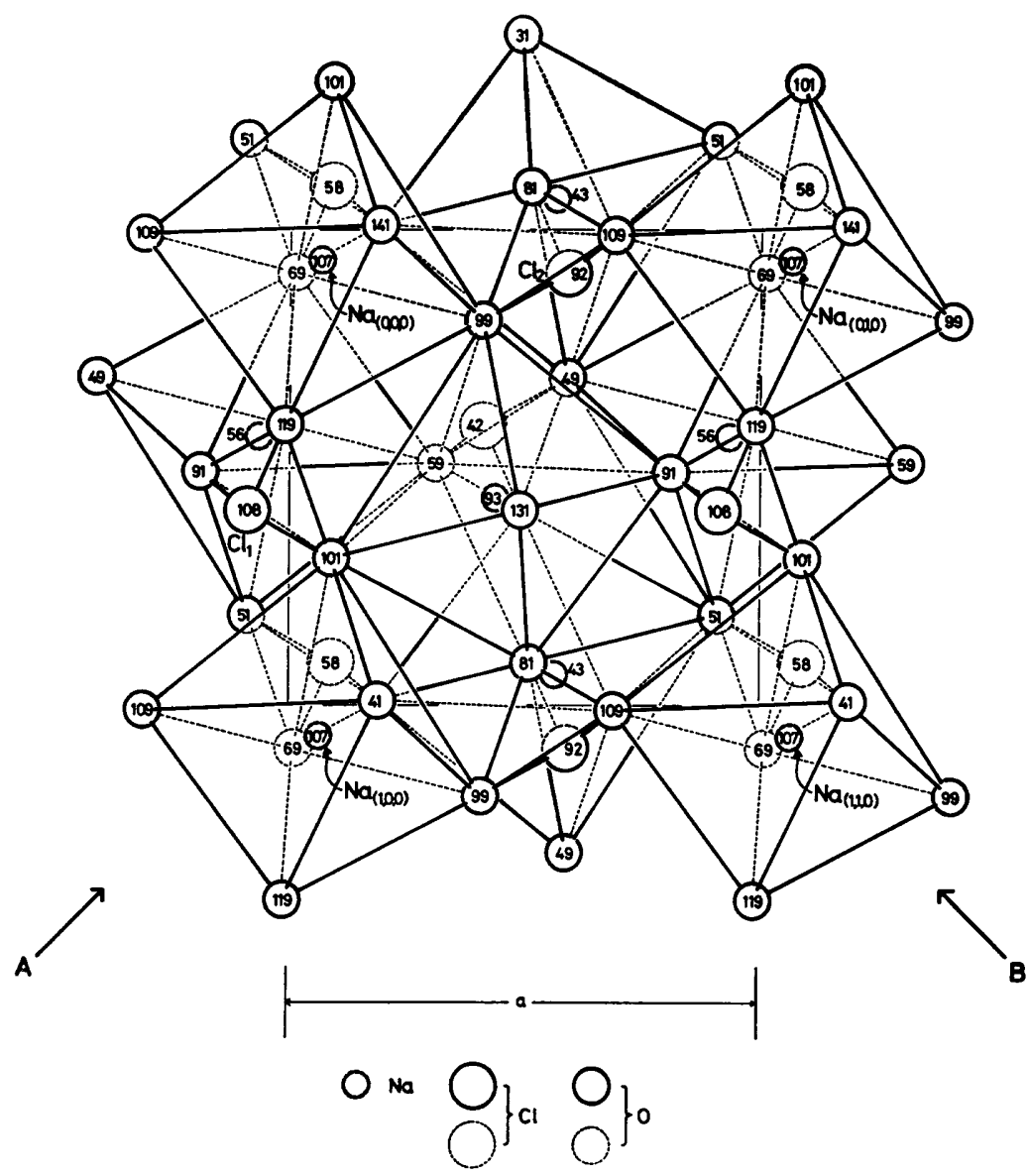

Fig, 20. Sodium chlorate structure as an array of distorted octahedra round $\mathrm{Na}^{+}$ions and flat pyramids of $\mathrm{ClO}_{3}{ }^{-}$ions projected on (001).

Zone circles corresponding to the directions of the principal linkage vectors are drawn on three stereograms in Fig. 21. In Fig. 21-A, 21-B, and 21-C, the poles of the faces of the trigonal pyramids, those of the octahedra projected on northern hemisphere, and on southern hemisphere are shown with the same zone circles, respectively. In these figures, the poles projected on northern hemisphere and on southern one are indicated by solid circles and open circles, respectively. And the size of a circle is illustrated to be proportional to the real surface area of a face of a coordination polyhedron.

The zone circles intersect at $\{111\}$ and $\{100\}$. In the case of the trigonal pyramids, the basal planes formed by three oxygen atoms are projected at $\{111\}$, and the pyramidal planes not at $\{111\}$ but near $\{111\}$ scatteredly. Among them, the northern poles are projected at and near (111) and (i11), but the southern ones at and near $(\overline{1} 1 \overline{1})$ and (1 $\overline{1} \overline{1})$ differentiatedly. To make clear, each region is marked by a large broken circle in Fig. 21-A.

While in the case of the distorted octahedron round $\mathrm{Na}$, the trigonal planes 


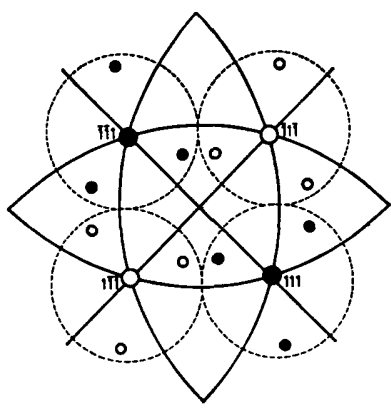

A

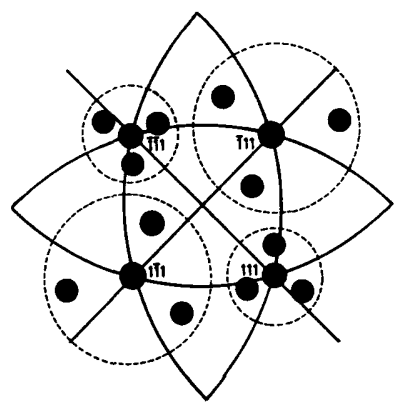

B

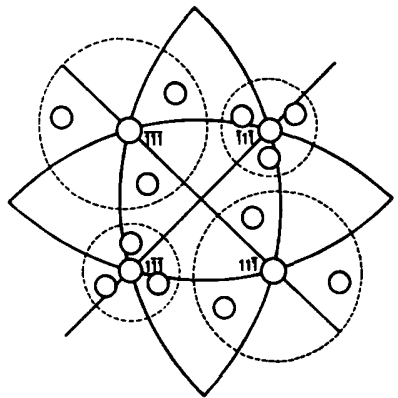

C

Fig. 21. Stereographic projections of zone circles corresponding to the directions of linkage vectors and of the faces of trigonal pyramids and those of octahedra round $\mathrm{Na}^{+}$ions in the sodium chlorate structure.

A. Zone circles and faces of trigonal pyramids.

B. Zone circles and northern poles of faces of octahedra round $\mathrm{Na}^{+}$ ions.

C. Zone circles and southern poles of faces of octahedra round $\mathrm{Na}^{+}$ ions.

forming octahedra are projected at and near $\{111\}$ (Fig. 21-B, 21-C). As shown in Fig. 21-B, the poles of the northern hemisphere are liable to concentrate at and

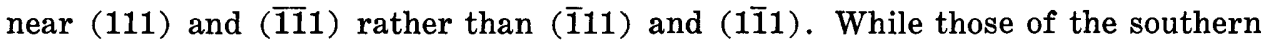

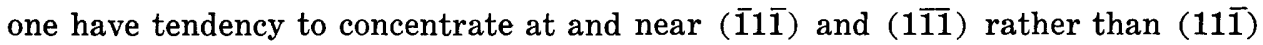
and (i11) (Fig. 21-C). These aspects are shown in Fig. 22, in which only the distorted octahedra are projected independently on (110) and (110) to become parallel to the four faces of $\{111\}$ form, respectively, namely, each figure is illustrated along an arrow $\mathrm{A}$ and $\mathrm{B}$ in Fig. 20.

These results indicate that (111), ( $\overline{11} 1),(\overline{1} 1 \overline{1})$, and $(1 \overline{1} \overline{1})$ are the faces having the same properties, and $(\overline{1} 11),(1 \overline{1} 1),(\overline{11} 1)$, and $(1 \overline{1})$ are the faces of the same properties different from the former four ones. When a sodium chlorate crystal grows from the highly supersaturated solution, the former four faces are 

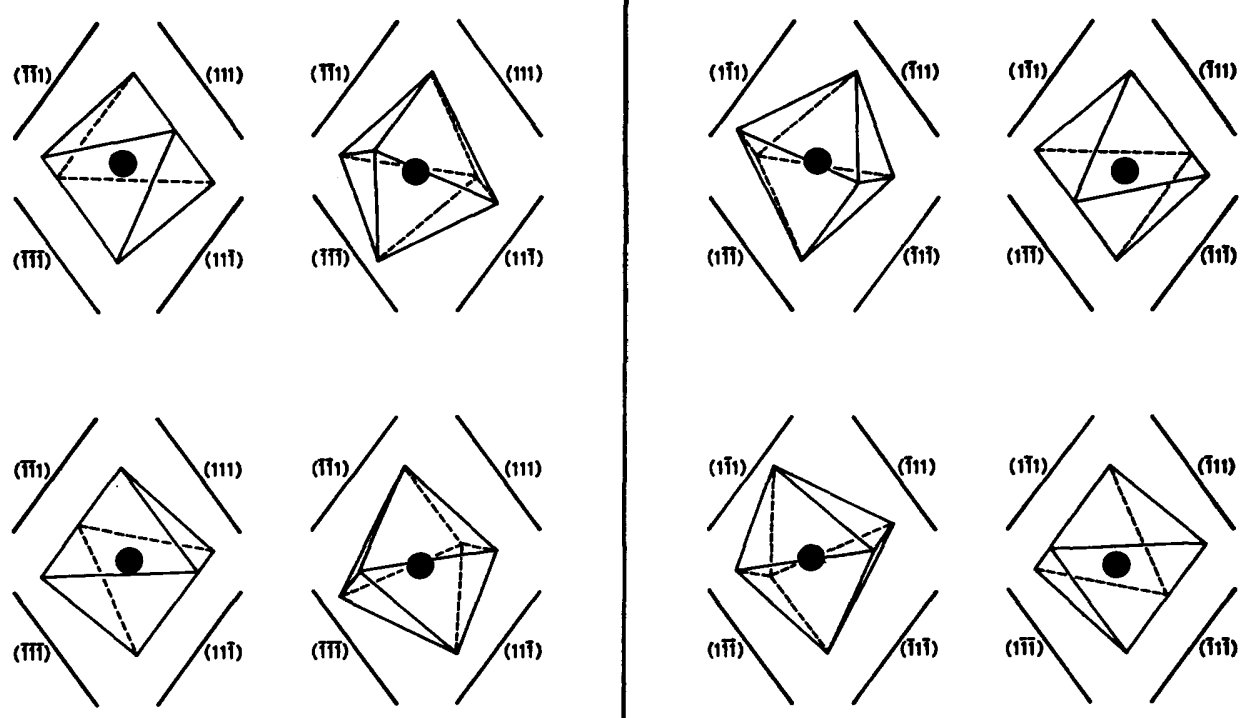

A

B

Fig. 22. Projection of distorted octahedra round $\mathrm{Na}^{+}$ions in the sodium chlorate structure on $\{110\}$.

A. (110) projection along an arrow A in Fig. 20.

B. (110) projection along an arrow B in Fig. 20.

expected to develop as the most important ones rather than the latter four ones among $\{111\}$ form. Hence, the sodium chlorate crystal is liable to have not octahedral but tetragonal habit.

\section{Comparison of the LCP Method with Experimental Data}

KERN (1953) and KERN (1955) have investigated the habit changes of many inorganic compounds grown from aqueous solution by changing degrees of supersaturation.

Observed forms of sodium chloride by them were $\{100\}$ and $\{111\}$ in the lower and in the higher supersaturation, respectively. The same results were obtained for another compounds with sodium chloride structure, for examples, $\mathrm{LiF}, \mathrm{KCl}$, $\mathrm{KBr}, \mathrm{KI}, \mathrm{NH}_{4} \mathrm{I}, \mathrm{RbCl}$, and RbI. Only in the case of $\mathrm{NaF}$, the combination form of $\{100\}$ and $\{111\}$ were observed along with minor forms of $\{133\},\{012\}$ and $\{112\}$ in the intermediate supersaturation. Consequently it can be said that all the crystals with sodium chloride structure have the morphology of $\{100\}$ and \{111\} when grown in the lower and the higher supersaturation, respectively, and in the intermediate supersaturation, their combination form is often observed. 
In the case of crystals having cesium chloride structure, the rhombic dodecahedral form $\{110\}$ and the cubic form $\{100\}$ are obtained, when aqueous solutions of $\mathrm{CsBr}, \mathrm{CsCl}$, or CsI are evaporated slowly and rapidly, respectively (KERN, 1952). These facts were qualitatively confirmed later by KERN (1953a, 1955b, 1968, and 1969).

There is only one experimental datum about the relation between the degree of supersaturation and the morphology of crystals with fluorite structure. When aqueous solution of $\mathrm{BaF}_{2}$ is evaporated slowly, the octahedral form $\{111\}$ is always obtained, but at high rate of evaporation the cubic form $\{100\}$ is obtained (KERN, 1953a).

As for calcite crystals, the morphological studies have been made by many investigators, especially regarding to natural occurrences and its crystallization stage (SUNAGAwa, 1954; KAShKaI and AlIEv, 1970; etc.). However, the experimental studies have been done by only a few investigators. According to a calcite synthesis by hydrothermal method (Pogodin and Dronov, 1975), the following habit changes were observed depending upon the change of the growth rate from high to low: the pinacoid $\{0001\} \rightarrow$ the principal rhombohedron $\{10 \overline{1} 1\} \rightarrow$ the prism $\{10 \overline{0} 0\}$, followed by various scalenohedra with the rhombohedron $\{01 \overline{1} 2\} \rightarrow$ the acute rhombohedron $\{02 \overline{2} 1\}$. This habit changes are in good agreement with the sequence of forms of natural calcites in the sequence of crystallization stage from earlier to later. While, when calcite crystals are synthesized by the method of counterdiffusion of $\mathrm{Ca}^{2+}$ and $\mathrm{CO}_{3}{ }^{2-}$ ions in $\mathrm{H}_{2} \mathrm{O}$, crystals grown in the presence of excess $\mathrm{CO}_{3}{ }^{2-}$ ions exhibit the habit varying from thick to fine tabular due to the considerable development of $\{0001\}$ (KIROV et al., 1972). These results indicate that calcite crystals tend to have the form of the pinacoid $\{0001\}$ when they grow under the conditions of high supersaturation or the presence of excess $\mathrm{CO}_{3}{ }^{2-}$.

Habit changes of crystals with the structure of $\mathrm{CdI}_{2}$, perovskite, or $\mathrm{NaClO}_{3}$ were studied experimentally by KERN (1955b). CdI 2 crystals grow with the form $\{0001\}$ limited by $\{01 \overline{1} l\}$ from the slightly supersaturated solution. The form $\{10 \overline{1} l\}$ becomes important with increasing the degree of supersaturation, and finally the form $\{10 \overline{1} 1\}$ develops largely (KERN, 1955b). However, judging from the photograph taken by him, $1 / 2\{10 \overline{1} 1\}$ seems to be the most important form of $\mathrm{CdI}_{2}$ crystals grown from highly supersaturated solution, although he describes the most important form as $\{10 \overline{1} 1\}$.

KERN (1955b) investigated the morphological changes of $\mathrm{KIO}_{3}$ and $\mathrm{RbIO}_{3}$ crystals grown from aqueous solution of which the crystals had the perovskite structure. They exhibit the form $\{100\}$ when grown from slightly supersaturated solution. With increasing the degree of supersaturation, the combination form of $\{100\}$ and $\{110\}$, subsequently $\{111\}$ appears, although the last form develops very easily.

In the case of $\mathrm{NaClO}_{3}$ crystals, the cube $\{100\}$ appears in the lower supersaturation. When the degree of supersaturation increases, the tetrahedral form $1 / 2\{111\}$ appears and soon prevails against the cube. KASATKIN (1963) obtained also the same result about $\mathrm{NaBrO}_{3}$ crystals as KERN did.

The results obtained by the LCP method are summarized together with ex- 
Table 1. Comparison of crystal morphology derived by the LCP method with experimental data

\begin{tabular}{|c|c|c|c|c|}
\hline \multirow{2}{*}{ Substance } & \multicolumn{2}{|c|}{ Experimental } & \multicolumn{2}{|c|}{ Theoretical } \\
\hline & 1 & 2 & 3 & 4 \\
\hline $\mathrm{NaCl}$ & $\{100\}^{a), b\rangle}$ & $\{111\}^{a), b)}$ & $\{100\}^{b), c), d)}$ & $\{111\}$ \\
\hline $\mathrm{CsCl}$ & $\{110\}^{a), b)}$ & $\{100\}^{a), b)}$ & $\{110\}^{b), c), d)}$ & $\{100\}$ \\
\hline Fluorite & $\{111\}^{(a), b)}$ & $\{100\}^{a), b)}$ & $\{111\}^{b), d)}$ & $\{100\}$ \\
\hline Calcite & $\{10 \overline{1} 1\}^{b), f)}$ & $\{0001\}^{b), e), f)}$ & $\{10 \overline{1} 1\}^{b), d)}$ & $\{0001\}$ with $\frac{1}{2}\{01 \overline{1} 2\}$ \\
\hline $\mathrm{CdI}_{2}$ & $\{0001\}^{b)}$ & $\frac{1}{2}\{10 \overline{1} 1\}^{b)}$ & $\{0001\}^{6)}$ & $\frac{1}{2}\{10 \overline{1} 1\}$ \\
\hline Perovskite & $\{\mathbf{1 0 0}\}^{b)}$ & $\{111\}^{b)}$ & $\{100\}^{b)}$ & $\{111\}$ with $\{100\}$ \\
\hline $\mathrm{NaClO}_{3}$ & $\{\mathbf{1 0 0}\}^{b)}$ & $\frac{1}{2}\{111\}^{b)}$ & $\{100\}^{b)}$ & $\frac{1}{2}\{111\}$ \\
\hline
\end{tabular}

1. Growth form in slightly supersaturated solution.

2. Growth form in highly supersaturated solution.

3. $F$-form by the HaRTMAN's method.

4. Crystal morphology derived by the LCP method.

a) KeRN, R. (1953). b) KeRN, R. (1955). c) Hartman, P. (1953).

d) Hartman, P. (1959). e) Kirov, G. K., et al. (1972).

f) Pogodin, YU. V. et al. (1975).

perimental data described above in Table 1 , in which important $F$-forms of each crystal by the HARTMAN's method are also given.

It is quite clear that the forms derived by the LCP method and the HARTMAN's one are in excellent agreement with those of crystals grown from highly and slightly supersaturated solutions, respectively. Both are the theoretical methods for predicting the crystal habits on the basis of crystal structure. Between the two, the HARTMAN's method lays emphasis on chains of strong bonds running through the structure for analyzing crystal habit; that is to say, the consisting element of a crystal is atoms. While, in the case of the LCP method, the element is coordination polyhedra, then the importance is in the linkages of the coordination polyhedra.

As described in the chapter II, when a crystal grows from slightly supersaturated solution, the strong bonds between atoms may have direct effects upon the crystal habit, while when a crystal grows from highly supersaturated solution, the clustering of ions may occur in solution and may affect a great influence on the crystal habit.

\section{Geological Applications}

In the former chapter, the validity of the LCP method has been verified by experimental data. Followings will give some applications of the LCP method together with the HARTMAN's method to geological phenomena. 


\section{A. Qualitative Estimation of Concentration Change of Mineralizing Solution}

Stability relations of minerals have been studied by many investigators and were thermodynamically established for a number of fields of metamorphism or ore mineralization. However, a study on concentration change of mineral forming fluids has never been done except for the fugacity changes of volatile materials, because there have been no ideas to know the concentration change of mineralizing solution.

In solution growth, the concentration change can be represented by the saturation ratio, $S$, in the following manner:

$$
C=\frac{C_{a}}{C_{e}}
$$

where $C_{a}$ and $C_{e}$ are the actual and the equilibrium concentration, respectively. Supersaturation in natural systems can be produced by addition of solute, by evaporation of solvent, by a temperature gradient, or by supercooling. The saturation ratio varies with effects of these phenomena.

On the other hand, the effect of the saturation ratio on the linear growth rate of a face $(h k l)$ of a crystal, $v_{h k l}$, can be represented by

$$
v_{h k l}=K u^{a} S^{n}
$$

where $K$ is a constant, $u$ is the solution velocity, and $a$ and $n$ are both functions of the solution velocity (MuLLIN, 1972).

Accordingly, the concentration change of mineralizing solution affects the growth rate of a crystal face, that is to say, the concentration change is indicated as the habit change of a crystal. Although the relation between the saturation ratio and the habit change of a crystal is not given quantitatively, their qualitative relation can be given by using both the LCP method and the HARTMAN's method. Namely, the habit deduced by the LCP method is that of a crystal grown from solution at high saturation ratio, and the habit derived by the HARTMAN's method is that at low saturation ratio as already described at the former chapter. In order to clearify the description, the formations of galena crystals in a few occurrences are briefly outlined below as examples.

The structure of galena is similar to that of sodium chloride, lead and sulfur atoms occupying the position of sodium and chlorine respectively (see Fig. 4). Thus, as same as in the case of sodium chloride, each lead atom is octahedrally coordinated by six sulfur atoms and each sulfur by six lead atoms. Therefore,

\section{Explanation of Plate 14}

A. Interference photomicrograph of triangular markings on natural (111) face of a cubo-octahedral crystal of galena. Ani mine, Akita Prefecture, Japan.

B. Rectangular growth hillocks on (001) face of galena from the Ani mine.

C. Rectangular growth spiral on (001) face of galena. Ashio mine, Tochigi Prefecture, Japan.

The crystallographic orientation shown by arrows is for the crystals of $B$ and $\mathrm{C}$. 
Mem. Fac. Sci., Kyushu Univ., Ser. D, Vol. XXIV, No. 2

Plate 14

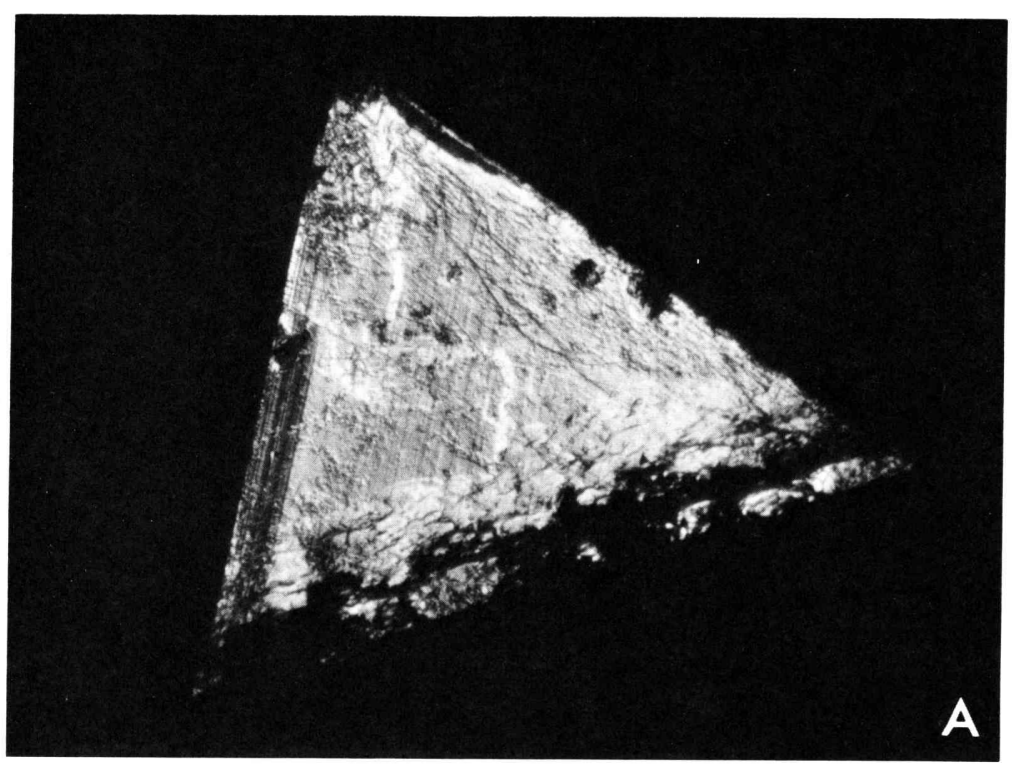

$0.5 \mathrm{~m} \mathrm{~m}$

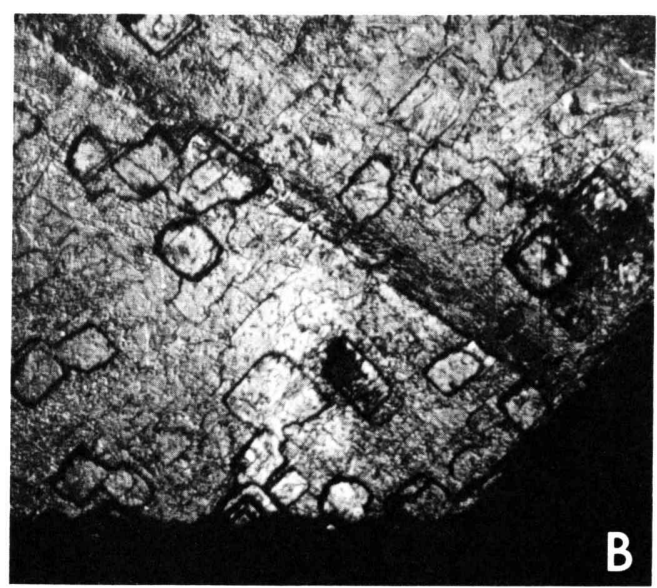

$0.5 \mathrm{~mm}$

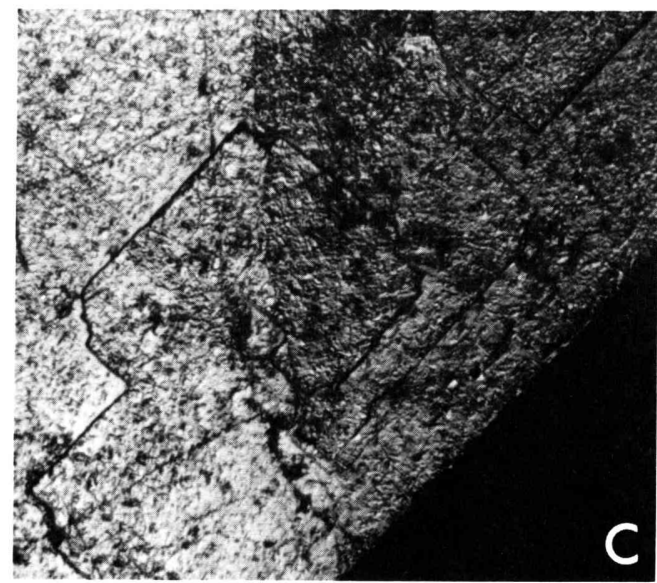

$0.3 \mathrm{~mm}$

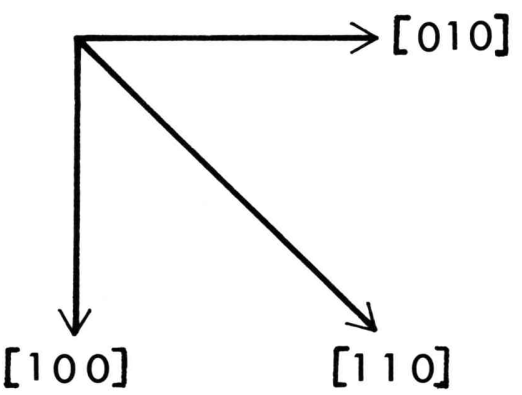

Y. AoKI : Morphology of Crystals 
galena crystals grown from the highly or slightly supersaturated solution tend to have the habit of $\{111\}$ or $\{100\}$ respectively like sodium chloride crystals.

Plate 14-B shows a topography of (001) surface of a galena crystal at the Ani mine, Akita Prefecture. This crystal occurs on crystalline quartz and chalcopyrite in the epithermal vein and has the habit of $\{100\}$ with small $\{111\}$ form.

Three facts are observed about (001) surface topography of this crystal:

(1) All the growth hillocks have the shape of square or rectangular.

(2) Their sides have the angle of $45^{\circ}$ with $\langle 100\rangle$ edges, and are parallel or perpendicular to $\langle 110\rangle$ edges.

(3) The $\langle 100\rangle$ edges have some rugged appearance, while the $\langle 110\rangle$ edges are smoother than the former.

These facts may indicate that the growth unit is a square shaped one having the angle of $45^{\circ}$ with $\langle 100\rangle$ edges.

When the layer growth or the spiral growth takes place on (001) of a galena crystal, the minimum growth unit is presumed to be a square shown as dotted lines in Fig. 23-A by the HARTMAN's method. However, the growth hillocks as shown in Plate 14-B could never been made by concentraitng these growth units.

Therefore, it is supposed that the growth unit is added on (100) surface by the angle of $45^{\circ}$ with $\langle 100\rangle$ edges, or that another shaped growth unit is added on (001) surface. In the former case, we can suppose to cut a galena crystal along (001) and let the upper half of the crystal lattice rotate about [001] at a lattice point chosen as the origin. According to the method of KRONBERG and WILSON (1949), each rotation of a lattice point $(l, m)$ into $(m, l)$ will generate a whole two-dimensional array of such coincident points which they call the coin-
() ()
(2)
(2) (2)
() ()
(2)
()
(2) (2)
()
()
()
() 0
$\left[\begin{array}{lll}0 & 0 & 0 \\ 0 & 0 & 0\end{array}\right.$
(2) ()
() ()
() 0
(-) 0
() 0
()
()
(-)
()

A

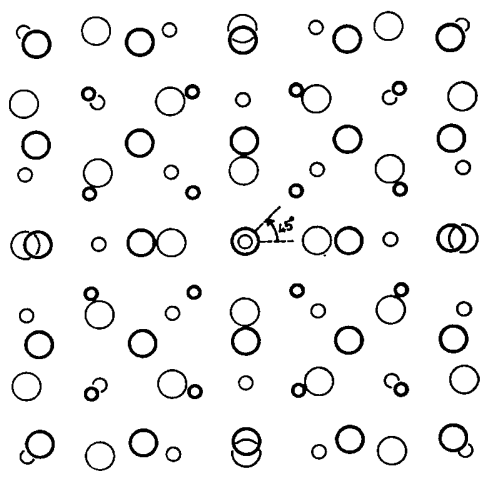

B

Fig. 23. Crystal structure of galena projected on (001). Small and large circles indicate lead and sulfur atoms, respectively.

A. Dotted lines indicate a growth unit by the HarTman's method. Circles drawn by narrow and thick lines show atoms at height of $\frac{1}{2}$, and 0 and 1 , respectively.

B. $45^{\circ}$ rotation of the upper half of the crystal lattice about (001). Circles drawn by narrow and broad lines show atoms belonging to the lower and the upper half of the crystal lattice, respectively. 
cidence lattice. Two parts of a crystal rotationally displaced by some angle of of rotation can form a twin in a metastable equilibrium only if the ratio of the size of the coincidence lattice cell to the original unit cell is small.

Fig. 23-B shows $45^{\circ}$ rotation of the upper half of the crystal lattice as an example. However, we can never get any coincidence-site lattice to form a twin in a metastable equilibrium on (001) surface of a galena crystal. Hence, the growth hillocks as shown in Plate 14-B can never been made by the growth unit derived by the HARTMAN's method.

Next, let us take up the growth unit derived by the LCP method. On (001) of a galena crystal, the linkage of coordination octahedra round lead atoms intersects each other at right angles and has an angle of $45^{\circ}$ with $\langle 100\rangle$ edges (Fig. 24-A). Therefore, a growth unit by the LCP method has a shape of a square as shown with dotted lines in Fig. 24-A and also has an angle of $45^{\circ}$ with $\langle 100\rangle$ edges. Then if growth hillocks or spirals are formed on (001) surface of a galena crystal by this growth units, they will become polygonal and have the shape of a square or a rectagular, and their sides will have an angle of $45^{\circ}$ with $\langle 100\rangle$ edges as schematically illustrated in Fig. 24-B. The growth hillocks shown in Plate 14-B may be formed in this manner.

Plate 14-C shows a topography of (001) surface of a galena crystal at the Ashio mine, Tochigi Prefecture. (001) of this crystal is surrounded by $\{111\}$ forms. A rectangular shaped spiral is observed on this face. The sides of the spiral are all parallel or perpendicular to $\langle 110\rangle$ edges. It also seems that the rectangular shaped growth spiral is formed by the growth units derived by the LCP method as the same manner as in the galena crystal at the Ani mine. The schematic illustration is shown in Fig. 24-C.

Now, the direction of the steps on (111) surface is parallel to that of the sides of triangular shape of (111) in galena crystals of the both mines. Plate 14-A shows a topography of (111) surface of a galena crystal at the Ani mine, for example.

Both galena crystals have the morphology of $\{100\}$ and $\{111\}$, although $\{100\}$ dominant in the Ani galena while $\{111\}$ dominant in the Ashio galena. And layer growth or spiral growth has taken place on $\{111\}$ and $\{100\}$ of both galena crystals with the growth unit derived by the LCP method. Consequently it can be concluded that both crystals have the intermediate morphology changing from $\{100\}$ to $\{111\}$, which indicates that the solution has changed the supersaturation from lower to higher during the growth of galena crystals. It may also be said that galena crystals have grown under the condition of increasing sulfur fugacity. Because, in lower sulfur fugacity, the bonding between lead and sulfur atoms will govern the growth of galena crystals, while in higher sulfur fugacity, sulfur atoms tend to concentrate round lead atoms and the linkages of coordination octahedra round lead atoms will govern the habit of crystals. Consequently, if a galena crystal under the condition of lower sulfur fugacity, it will take the habit of $\{100\}$. While if it grows in higher sulfur fugacity, it will have the habit of $\{111\}$. Then, the habits of galena crystals of both mines indicate the change of sulfur fugacity from lower to higher. 


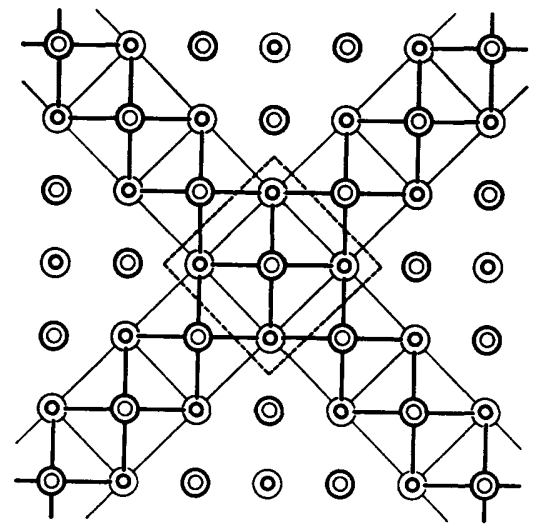

A

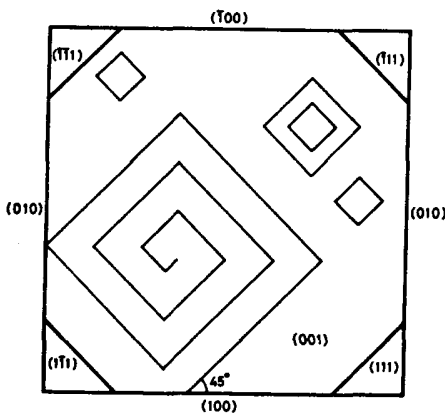

B

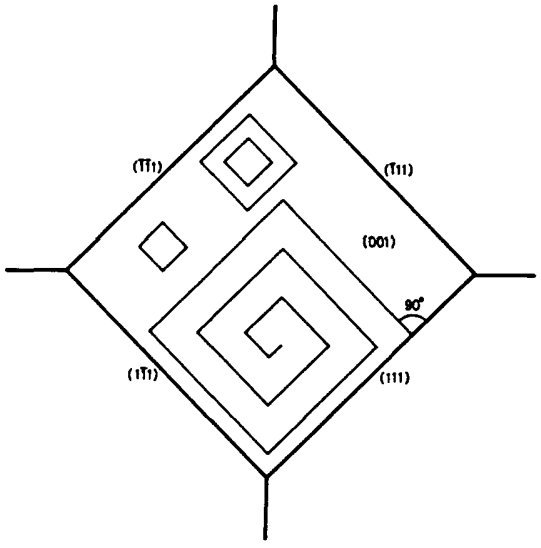

C

Fig. 24. Growth unit derivation by the LCP method and schematic illustration of topography of (001) surface of a galena crystal.

A. Linking aspect of coordination octahedra round lead atoms and the growth unit derived by the LCP method which is shown by dotted lines at the center of the figure.

B. and C. Schematic illustrations of the topography of (001) surface surrounded by $\{100\}$ with small $\{111\}$ forms and by only $\{111\}$ form, respectively. If growth hillocks and spirals are formed by the growth units of Fig. 24-A, it is predicted that they are illustrated schematically like in the Fig. 24-B or -C.

\section{B. Mechanism of Formation of Growth Twins}

BUERGER (1945) set up the following types of twins from their geneses: growth twins, transformation twins, and gliding twins. Among them, the latter two have been studied very actively by many crystallographers, metallurgists, mineralogists, and so on. As for the growth twins, little is known about the 
mechanism of formation, although there are many morphological or crystallographical studies. Especially there are not enough experimental data for proving the hypothesis for the formation of growth twins.

HARTMAN (1956b) applied the PBC vector analysis to the morphology of growth twins and concluded that when twinning started on a face, this face must be an $F$-face or, less frequently, $S$-face. The mechanism of formation of contact twins could be explained by his method in fairly good agreement with observational data, but that of penetration twins was not explained.

KERN (1961) studied the formation of growth twins from the geometrical and thermodynamical points of view. He called the crystal surface on which a two-dimensional twin nucleus occurs "plan de composition originel (PCO)" and the row involved in the PCO and in common with two individuals "rangee de composition originelle (RCO)". And a twin of which the PCO is identical with the twin plane is called a contact twin, and a twin of which the PCO is not a symmetry plane for two individuals is called a penetration twin. However, as same as HARTMAN could not do, he could not also explain clearly the mechanism of formation of penetration twins.

Their failures are due not to take into account the habit changes during the formation of growth twins.

Here, we suppose following two phenomena capable to occur for the formation of growth twins that growth twins are formed by only two individuals adhereing together, and that the habit changes often take place in accordance with change of the environment during the growth of twins as SENECHAL (1976) inferred.

Fig. 25 indicates a schematic illustration of the process and the mechanism of the growth twin formation of galena for example explained on the basis of above assumptions.

Stage
(1)
(2)
(3)
(4)
(5)
(6)
(7)

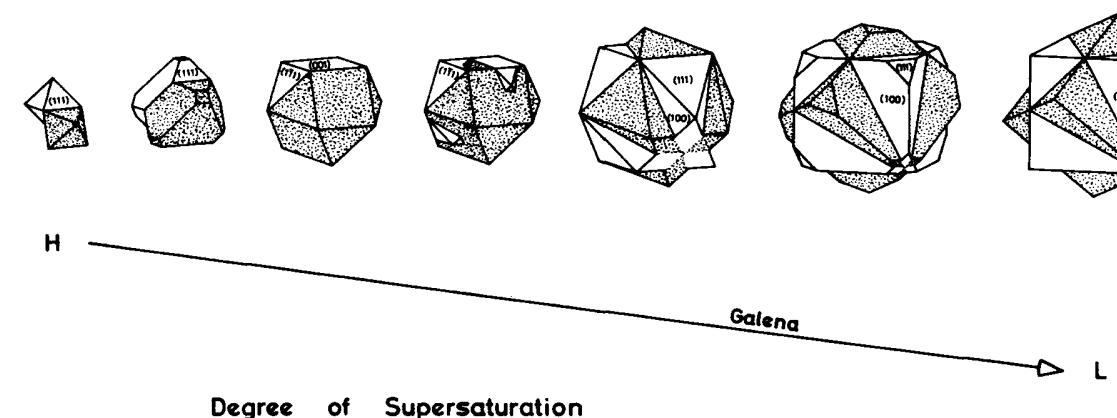

Fig. 25. Schematic illustration of process and mechanism of formation of contact and penetration twins of galena. 
In the case of galena, penetration and contact twins with twin plane $\{111\}$ are often found in nature (PALACHE et al., 1949). The penetration and contact twins have the morphologies such as that of stage-(6) and stage-(2) in Fig. 25, respectively. The habit of each individual of penetration twins is cube and that of contact twins is octahedron.

When galena crystals grow in the highly supersaturated solution, they take the habit of $\{111\}$ as indicated by the LCP method. If two individuals adhered each other with $\{111\}$ forms like stage-(1) in Fig. 25, a contact twin will be formed. It is the nucleation stage of the formation of a contact twin.

With decreasing the degree of supersaturation, $\{100\}$ will appear and develop since $\{100\}$ is the important form for galena crystals grown from slightly supersaturated solution.

In most cases, dislocations are concentrated at the twin boundary and steps or kinks occur at the boundary between two individuals because the growth rates of two individuals are not identical. Then the twin boundary has tendency to become the most important active site for crystal growth. Therefore, the individual-I may grow over the individual-II from the twin boundary and similarly the individual-II over the individual-I like stage-(4) in Fig. 25. This is the nucleation stage of the formation of a penetration twin.

When the growth occurs moreover and the degree of supersaturation continues to decrease, $\{\mathbf{1 0 0}\}$ will develop more and more. Finally, we will obtain the penetration twins formed by two cubes when $\{111\}$ disappeared (stage- $(7)$ in Fig. 25).

In this process, if the galena crystals stop to grow at the stage-(2), we will have the contact twins of galena. If they grow up to the stage-(6) or -(7), we will obtain the penetration twins. However, if it follows the inverse sequence, the penetration twins can never been formed.

Here, the degree of supersaturation indicated in Fig. 25 can be replaced by the fugacity of sulfur. It seems that sulfur atoms tend to concentrate round lead atoms under the condition of higher sulfur fugacity, that is, the coordination octahedra round lead atoms are formed with ease, but in lower sulfur fugacity, the bonding between lead and sulfur atoms will become a dominant factor for the growth of galena crystals. Consequently, the galena crystal will take the habit of $\{111\}$ or $\{100\}$ under higher or lower sulfur fugacity, respectively, as derived by the LCP method and the HARTMAN's method.

In the similar manner, mechanism of the formation of contact and/or penetration twins of another materials are also explained clearly. The most important point of this hypothesis about the formation of growth twins is that both contact and penetration twins may be formed as a result of habit change during growth by only one process under the condition of concentration change or fugacity change of mineralizing fluid.

\section{Concluding Remarks}

From the historical approach about the theories for crystal morphology, it became clear that equilibrium forms or forms grown from slightly supersaturated 
solution could have been analyzed by the HARTMAN's method, but those grown from highly supersaturated solution were difficult to analyze by any theoretical methods already known.

However, this study reveals that the habit of a crystal grown from highly supersaturated solution can be evaluated by introducing the linkages of coordination polyhedra for the morphological analysis on the basis of crystal structure.

It is concluded that the habit of a crystal grown from highly supersaturated solution is governed by the linkages of coordination polyhedra, running through the structure in a limited number of directions. Such a vector of linkages having a direction and an energetical period is called a linkage vector. If a given face is parallel to at least two non-parallel linkage vectors, it is possible to be an important face. Especially if the face is parallel or nearly parallel to some faces of coordination polyhedra, it becomes an important face.

Some examples of crystal habit deduced by this method are given in chapter III and compared with experimental data in excellent agreement. Here, it has become clear that the habit of a crystal grown from highly or slightly supersaturated solution corresponds to that derived by this method and by the HARTMAN's method, respectively. That is, the habit of a crystal is governed by linkages of coordination polyhedra in higher supersaturation and by chains of strong bonds between atoms in lower supersaturation. In intermediate supersaturation, the habit of a crystal may be governed by the probability of formation of coordination polyhedra and/or of strong bond chains among atoms.

By applying the LCP method together with the HARTMAN's method, concentration change of mineralizing solution was qualitatively estimated in relation to the surface topography observed on (001) of galena crystals at the Ani and the Ashio mines. As a result of the observations, it has been proved that galena crystals of both mines have grown under the condition from lower to higher supersaturation or of increasing sulfur fugacity.

The LCP method was also applied to analyze the mechanism of formation of growth twins, and that of contact and penetration twins was explained clearly by only one process under the condition of concentration change or fugacity change of mineralizing fluid.

\section{Acknowledgements}

The author wishes to thank Professors Haruo SHIRozU of the Kyushu University, Hitoshi MomoI of the Ehime University, and Ichiro SunAGAWA of the Tohoku University for critical reading the manuscript, helpful comments and discussions, and encouragement. The author is also grateful to Mrs. Eiko Tsukinoki for typewriting the table and some sentences.

\section{References Cited}

BAUmhaUER, H. (1904): Untersuchungen über die Entwickelung der Kristallflächen im Zonenverbande. Z. Kristallogr., 38, 628-655.

(1925) : Beitrage zur vergleichenden Kristallographie. Schweiz. Min. Petr. Mitt., 5, 348-426. 
Bessieres, J. et BARo, R. (1973) : Détermination de la forme d'équilibre de cristaux d'hématite $\alpha-\mathrm{Fe}_{2} \mathrm{O}_{3}$. J. Cryst. Growth, 18, 225-236.

Bienfait, M., Boistelle, R. et KeRN, R. (1963) : Morphodrome de $\mathrm{NaCl}$ en présence des ions ferri- et ferrocyanure. C. R. Acad. Sci. Paris, 256, 2189-2192.

BraDY, G. W. (1958) : Structure in ionic solutions. III. J. Chem. Phys., 29, 1371-1375.

BragG, W. L .(1914): The analysis of crystals by the X-ray spectrometer. Proc. Roy. Soc. London, A89, 468-489.

Bbavais, A. (1866) : Études cristallographiques. Gautier-Villars, Paris.

Buerger, M. J. (1945) : The genesis of twin crystals. Amer. Mineral., 30, 469-482. (1947): The relative importance of the several faces of a crystal. Amer. Mineral., 32, 593-606.

BunN, C. W. (1933) : Adsorption, oriented overgrowth and mixed crystal formation. Proc. Roy. Soc. London, A141, 567-593.

- (1949): Crystal growth from solution. Disc. Faraday Soc., No. 5, 132-144.

Debye, P. and Hücker, E. (1923): Zur Theorie der Elektrolyte. I. Physik Zeit., 24, 185-206.

Donnay, J. D. H. (1937) : The crystallographic series of Baumhauer and Ungemach, a theoretical consequence and factual confirmation of the law of Bravais. Amer. Mineral., 22, 209-210.

- and HARKeR, D. (1937): A new law of crystal morphology extending the law of Bravais. Amer. Mineral., 22, 446-467.

Fedorov, E. S. voN (1912): Die Praxis in der Kristallochemischen Analyse und die Abfassung der Tabellen für dieselbe. Z. Kristallogr., 50, 513-575. (1920): Das Kristallreich. Mem. Acad. Sci. Russ. 8th Ser., 36.

Friedel, G. (1907) : Études sur la loi de bravais. Bull. Soc. franç. Min., 20, 326-455.

GibBs, J. W. (1906): On the equilibrium of heterogeneous substances. The Scientific Papers of J.W. Gibbs, Vol. 1. Thermodynamics. Longmans, London.

GoLDSchмIDT, V. (1897) : Ueber Entwickelung der Kristallformen. Z. Kristallogr., 28, $1-35$.

HARTMaN, P. (1953) : Relations between structure and morphology of crystals. Thesis, Groningen.

(1956a): The morphology of zircon and potassium dihydrogen phosphate in relation to the crystal structure. Acta. Cryst., 9, 721-727.

(1956b) : The morphology of growth twins. Z. Kristallogr., 107, 225-237.

(1959a): Über die Gleichgewichtsformen einiger Ionenkristalle. N. Jb. Min. Monatsch., 1959, 73-84.

(1959b) : La morphologie structurale du quartz. Bull. Soc. franc. Minér. Crist., 82, 335-340.

and Perdok, W. G. (1955) : On the relations between structure and morphology of crystals. Acta Cryst., 8, 49-52; 521-524; 525-529.

Hester, R. E. and Plane, R. A. (1964) : Raman spectrophotometric study of complex formation in aqueous solutions of calcium nitrate. J. Chem. Phys., 40, 411-414.

Hester, R. E. and SCAIFE, C. W. J. (1967) : Vibrational spectra of molten salts. III. Infrared and Raman spectra of variably hydrated zinc nitrate. J. Chem. Phys., 47, 5253-5258.

IRISH, D. E. and DAVIS, A. R. (1968): Interactions in aqueous alkali metal nitrate solutions. Canad. J. Chem., 46, 943-951.

KAsAtKIN, A. P. (1963) : Growth rate of the $\mathrm{NaBrO}_{3}$ crystal faces as function of temperature and supersaturation. Vestn. Leningr. Univ., 18, Ser. Geol. i geogr., No. 4, 134-136 (Chem. Abstr. 60-9987e (1964)).

KAshkaI, M. A. and Aliev, R. M. (1970) : Structural analysis of the commonly encountered habit faces of calcite crystals from skarn deposits. Min. Mag., 37, 929-933.

KERN, R. (1952): Influence de la vitesse d'evaporation de solutions d'halogénures alcalins type $\mathrm{CsCl}$ sur le faciès des cristaux obtenus. C. R. Acad. Sci. Paris, 234, 1696-1697. 
(1953) : Étude du faciès de quelques cristaux ioniques a structure simple. Bull. Soc. franç. Minér. Crist., 76, 325-364; 391-414.

(1955): Influence du milieu de croissance sur la correspondance entre morphologie et structure cristalline. Bull. Soc. franç. Minér. Crist., 78, 461-474; 497-520.

(1961): Sur la formation des macles de croissance. Bull. Soc. franç. Minér. Crist., 84, 292-311.

(1968) : Croissance cristalline et adsorption. Bull. Soc. franç. Minér. Crist., 91, 247-266.

(1969) : Crystal growth and adsorption. In N. N. ShefTaL' (ed.): Growth of Crystals, Vol. 8, 3-23. Consultants Bureau, New York.

Kirov, G. K., Vesselinov, I. and Cherneva, Z. (1972) : Conditions of formation of calcite crystals of tabular and acute rhombohedral habits. Krist. Tech., 7, 497509.

Kronberg, M. L. and Wilson, F. H. (1949) : Secondary recrystallization in copper. Trans. AIME, 185, 501-514.

LEVY, H. A. and DANFoRD, M. D. (1964) : Diffraction studies of the structure of molten salts. In M. BLANDER ed.) : Molten Salt Chemistry, 109-126. Interscience Publ., New York.

Lippmann, F. (1973) : Sedimentary Carbonate Minerals. Springer-Verlag, Berlin.

Muluin, J. W. (1972) : Crystallization (2nd ed.). Butterworths, London.

NIGGLI, P. (1919): Geometrische Kristallographie des Diskontinuums. Borntraeger, Leipzig.

- (1920): Beziehung zwischen Wachstumsformen und Struktur der Kristalle. $Z$. anorg. allgem. Chemie, 110, 55-80.

Palache, C., Berman, H. and Frondel, C. (1944): The System of Mineralogy (7th ed.). Vol.1. John Wiley, New York.

Pogodin, Yu. V. and Dronov, V. V. (1975): Growth of optical calcite from seeds with various orientations. In N. N. SheFtaL' and E. I. Givatgizov (ed.): Growth of Crystals, Vol. 9, 55-61. Consultants Bureau, New York.

SenECHAL, M. L. (1976) : The mechanism of formation of certain growth twins of the penetration type. $N$. Jb. Miner. Mh., 1976, 518-524.

Simon, B. et Bienfait, M. (1965): Structure et méchanism de croissance du gypse. Acta Cryst., 19, 750-756.

SUNAGAWA, I. (1953) : Variation of crystal habit of calcite with special reference to the relation between crystal habit and crystallization stage. Rept. Geol. Surv. Japan, No. 155, 1-66 (in Japanese with English abstract).

Wells, A. F. (1946) : Crystal habit and internal structure. Phil. Mag., 37, 184-199; $217-236 ; 605-630$.

Wyckoff, R. W. G. (1963) : Crystal Structures, Vol. 1 (2nd ed.). Interscience Publ., New York. 